Age Discrimination Laws and Labor Market Efficiency

Author(s): David Neumark and Wendy A. Stock

Source: The Journal of Political Economy, Vol. 107, No. 5, (Oct., 1999), pp. 1081-1125

Published by: The University of Chicago Press

Stable URL: http://www.jstor.org/stable/2990839

Accessed: 22/04/2008 14:04

Your use of the JSTOR archive indicates your acceptance of JSTOR's Terms and Conditions of Use, available at http://www.jstor.org/page/info/about/policies/terms.jsp. JSTOR's Terms and Conditions of Use provides, in part, that unless you have obtained prior permission, you may not download an entire issue of a journal or multiple copies of articles, and you may use content in the JSTOR archive only for your personal, non-commercial use.

Please contact the publisher regarding any further use of this work. Publisher contact information may be obtained at http://www.jstor.org/action/showPublisher?publisherCode=ucpress.

Each copy of any part of a JSTOR transmission must contain the same copyright notice that appears on the screen or printed page of such transmission.

JSTOR is a not-for-profit organization founded in 1995 to build trusted digital archives for scholarship. We enable the scholarly community to preserve their work and the materials they rely upon, and to build a common research platform that promotes the discovery and use of these resources. For more information about JSTOR, please contact support@jstor.org. 


\title{
Age Discrimination Laws and Labor Market Efficiency
}

\section{David Neumark}

Michigan State University and National Bureau of Economic Research

\section{Wendy A. Stock}

Kansas State University

\begin{abstract}
In Lazear's model of long-term incentive contracts, age discrimination laws barring age-based involuntary terminations preclude such contracts, reducing efficiency. Alternatively, such laws may serve as precommitment devices for these contracts, without preventing firms from offering strong financial incentives to induce retirement at specific ages. In this case, age discrimination laws may encourage Lazear contracts, hence increasing efficiency. We assess evidence on these alternative interpretations using variation in state and federal age discrimination laws. The evidence indicates that age discrimination laws steepen age-earnings profiles for cohorts entering the labor market, suggesting that these laws encourage the use of Lazear contracts.
\end{abstract}

\section{Introduction}

The Age Discrimination in Employment Act (ADEA) was enacted by Congress in 1968 to "promote employment of older persons based on their ability rather than age; to prohibit arbitrary age discrimination in employment; to help employers and workers find ways of meeting problems arising from the impact of age on employment." Although the intent of the ADEA was to ban age discrimination, influential research by Lazear (1979) pointed out that the law

We received helpful comments from Kathleen Beegle, Rosella Gardecki, Bob Topel, an anonymous referee, and seminar participants at Michigan State, the University of Michigan, and Kansas State. Neumark gratefully acknowledges support from National Institute on Aging grant K01-AG00589 and from the University of Michigan Population Studies Center. 
may have had other consequences that benefited currently older workers but impaired efficiency. In Lazear's model, with efficient long-term incentive contracts ("Lazear contracts"), older workers earn more than their marginal product and more than their reservation wage, whereas younger workers earn less than their marginal product. Thus this model can generate rising age-earnings profiles even if age-productivity profiles are flat or declining. But the model also provides insight into the potential effects of age discrimination laws. Specifically, because older workers earn more than their reservation wage, an implication of prohibiting involuntary retirement based on age is that older workers "will enjoy a small once-and-forall gain at the expense of a much larger and continuing efficiency loss that affects all workers and firms adversely" (Lazear 1979, pp. $1283-84){ }^{1}$

There are other considerations, however, that suggest that legislation barring age discrimination may encourage, rather than discourage, the formation of Lazear contracts. Some empirical research suggests that mandatory retirement was not an important determinant of retirement age. Despite restrictions on involuntary retirement based on age, firms have remained able to offer financial incentives to induce retirement at specific ages. Finally, the ADEA also prohibited age discrimination in layoffs, which may have inhibited firms from opportunistically reneging on long-term implicit contracts with older workers. As such, the ADEA may serve as a "precommitment" mechanism of the type studied by Schelling $(1978,1983)$. With its prohibition of age-based firings providing a means for workers to enforce Lazear-type contracts, the ADEA may encourage workers to enter into such contracts and hence increase rather than decrease labor market efficiency.

This paper evaluates these two competing views of age discrimination laws by considering the effects of such laws on a proxy for the use of Lazear contracts: the steepness of age-earnings profiles. Our identifying information comes from the many states that passed laws barring age discrimination prior to the federal legislation. Under the assumption that the slopes of productivity profiles are unaffected, if age discrimination laws inhibit the formation of Lazear contracts and thus reduce labor market efficiency, they should lead to flatter earnings profiles. In contrast, if they strengthen the bonds between workers and firms, such laws should increase efficiency by encouraging Lazear contracts and lead to steeper earnings profiles.

${ }^{1}$ Although difficult to test in the absence of productivity measures, there is much evidence that is at least consistent with Lazear's model of rising age-earnings profiles (e.g., Medoff and Abraham 1980; Kotlikoff and Wise 1985; Kotlikoff and Gokhale 1992; Hellerstein, Neumark, and Troske 1999). 


\section{Interpreting Age Discrimination Laws}

To provide a framework for thinking about the effects of age discrimination laws such as the ADEA, we consider a version of Lazear's model based on Lang (1989). To simplify the analysis, hours choices are eliminated. The notation is as follows: $v_{t}$ is the worker's marginal revenue product in period $t, w_{t}$ is the wage, $s_{t}$ is the utility of leisure, $e_{t}$ is the disutility of effort, $q_{t}$ is the probability of detection and firing, $i$ is the discount rate of workers (constant), $r$ is the discount rate of firms (constant), $P_{T}$ is the pension paid at the end of the last period $(T)$, and $b$ is the bond posted by workers at the beginning of the first period.

Workers have an intertemporally separable utility function $u_{t}=$ $w_{t}-e_{t}-s_{t}$. The variable $R_{t}$ is the "surplus" to a worker in period $t$ from keeping his or her job, which is equal to

$$
R_{t}=\sum_{j=t+1}^{T}\left[\frac{w_{j}-e_{j}-s_{j}}{(1+i)^{j-t}}\right]+\frac{P_{T}}{(1+i)^{T-t+1}} .
$$

The no-shirk condition in each period $t$ is

$$
w_{t}-e_{t}-s_{t}+R_{t} \geq w_{t}-s_{t}+\left(1-q_{t}\right) R_{t} .
$$

Firms are assumed to hire a single worker, choosing a bond $(b)$, wage profile $\left(w_{t}, t=1, \ldots, T\right)$, pension $\left(P_{T}\right)$, and retirement date $(T)$. Labor is the only input to the production process. The firm maximizes the present discounted value of profits, subject to the constraint that the worker's utility is greater than or equal to that in the competitive sector and that the no-shirk condition holds in each period.

Lazear (1979) considers the case of costless bonding, captured in this model by setting $i=r$; for example, workers do not fear that firms may renege on long-term contracts and hence do not discount the future more heavily than firms. The implications of costless bonding in this framework match those derived by Lazear in a continuous-time setting. When $i=r$, the no-shirk condition need not be binding in every period. On the other hand, the constraint with respect to the competitive level of utility is binding. Thus the optimal solution with respect to the wage profile, bond, and pension is characterized only by the constraint that workers receive utility equal to that in the competitive sector. Other than this, the structure of the compensation package is indeterminate; in particular, nothing discourages back-loading of contracts.

The profit-maximizing choice of a retirement date $(T)$ implies that mandatory retirement occurs when the worker's marginal prod- 
uct is equal to the disutility of work, or $v_{T}=e_{T}+s_{T}$, which is required for efficiency. Workers are willing to accept retirement at $T$ ex ante, but ex post it is involuntary, which is the basis of Lazear's critique of the ADEA. Specifically, if long-term incentive contracts with involuntary retirement are efficient, then legislation that precludes this involuntary retirement must reduce efficiency. ${ }^{2}$

Despite the negative theoretical implications of age discrimination laws in Lazear's model, these laws may, in fact, have had little impact on firms' ability to induce retirement. First, firms have remained able to offer financial incentives to induce retirement at specific ages (Burkhauser and Quinn 1983; Fields and Mitchell 1984; Kotlikoff and Wise 1985, 1989; Lazear 1985; Mitchell and Fields 1985; Nalebuff and Zeckhauser 1985; Gustman and Steinmeier 1986; Slade 1987; Hurd 1990; Rees and Smith 1991) ${ }^{3}$ Second, much research suggests that mandatory retirement was generally unimportant in inducing retirement for all but a small percentage of workers (e.g., Burkhauser and Quinn 1983; Fields and Mitchell 1986; Ruhm 1990). Finally, in work subsequent to his 1979 paper, Lazear (1995) shows that efficient pension plans can achieve the same goals as mandatory retirement. Thus one could argue that the ADEA did little in the way of eliminating mandatory retirement, except in name, making largely inoperative the primary channel through which age discrimination laws reduce efficiency in Lazear's model. ${ }^{4}$

On the other hand, age discrimination laws may have beneficial effects. Consider the case in which bonding in the model laid out above is costly; with some possibility of firms reneging on long-term contracts, workers discount future flows of utility or income more heavily than firms, so that $i>r$. The introduction of costly bonding has important implications for the optimal wage profile and retirement age. First, the structure of the compensation package becomes determinate because the no-shirk condition is binding in each period. If we solve for $w_{T}, w_{T-1}$, and so forth, we find (by induction)

${ }^{2}$ Lazear's critique specifically referred to raising (and eventually eliminating) the mandatory retirement age. But as a general matter, age discrimination laws impair firms' ability to impose involuntary (ex post) retirement and hence entail efficiency losses in his model.

${ }^{3}$ The legality of financial inducements to retire under the ADEA is codified in the 1990 Older Workers Benefit Protection Act, which specified conditions that such incentives must satisfy (Albert and Schelberg 1989; Ford and Horn 1992).

${ }^{4}$ As a consequence, age discrimination laws might be expected to increase the extent to which pensions incorporate inducements to retire (Lazear 1995, chap. 4). We do not have the required information to test this proposition in our data set and hence leave it to future research. 
the general expression

$$
w_{t}=e_{t}+s_{t}+\frac{(1+i) e_{t-1}}{q_{t-1}}-\frac{e_{t}}{q_{t}} .
$$

We can similarly solve for $b$ and $P_{T}$.

Second, with costly bonding $(i>r)$, the date of involuntary retirement satisfies

$$
v_{T}=e_{T}+s_{T}+\frac{(i-r) e_{T}}{(1+r) q_{T}},
$$

so that it occurs when the worker's marginal product exceeds the disutility of work and effort $\left(e_{T}+s_{T}\right)$. Under the usual assumption in these models that $e_{t}+s_{t}$ rises faster than $v_{t}$, retirement occurs too early.

The model with costly bonding points to the potential efficiency gains offered by age discrimination laws. By prohibiting age discrimination in layoffs, such laws reduce the ability of firms to renege on long-term implicit contracts with older workers. This reduces bonding costs, lowering the rate $(i)$ at which workers discount future income. As equation (4) shows, a reduction in the costs of bonding increases efficiency by bringing the marginal product and the marginal disutility of labor closer together.

It is often argued that reputation effects deter firms from reneging on long-term contracts. But this ignores the possibility of an information asymmetry between firms and workers. Suppose that the marginal revenue product of workers at a firm in each period is subject to random demand shocks. With the same information structure as in Holmstrom (1981), the firm has an incentive to claim that a negative demand shock has occurred and that older workers must be retired at an earlier age than was "agreed" on in the initial contract. Because of the information asymmetry, workers may never learn the truth regarding the demand shock, in which case reputation effects cannot be completely effective.

But prohibiting age-based terminations may eliminate the incentive for firms to falsely claim negative demand shocks as a pretext to fire older workers. Firms are much less likely to find this in their interest since they would have to lay off workers paid more than their marginal products (older workers) and workers paid less than their marginal products (younger workers). Thus the ADEA may serve as a "precommitment" mechanism (Schelling 1978, 1983). Such mechanisms may serve the long-term interests of both parties, whereas in their absence, one or both parties might make short- 
term decisions that are ultimately detrimental to themselves. Firms may promise not to renege on long-term contracts. Although reputation effects might, in principle, enforce this promise, with asymmetric information (or other factors impeding reputation effects), workers may not trust firms. However, the prohibition of age-based firings may provide a means for workers to enforce long-term contracts, making workers willing to enter into them. Therefore, a perspective on age discrimination laws that focuses on the prohibition of opportunistic age-based terminations suggests that rather than discouraging long-term incentive contracts, such laws may encourage the formation of such contracts and, hence, increase efficiency. ${ }^{5}$

\section{The Empirical Test}

Ideally, assessing these alternative views of age discrimination laws requires evidence on the effects of these laws on the formation of Lazear contracts. Because such contracts are implicit, the best we can hope for is observable proxies. Therefore, the empirical analysis focuses on the effects of such legislation on the steepness of ageearnings profiles. As in other research on Lazear contracts, the presumption is that earnings profiles should become flatter if the predominant effect of the prohibition of age discrimination is to eliminate or reduce involuntary terminations of older workers and thus reduce the use of long-term incentive contracts (see, e.g., Lazear and Moore 1984) ${ }^{6}$ On the other hand, if the principal effect of age discrimination laws is to reduce bonding costs, then profiles will steepen.

While estimating the effects of age discrimination laws on the slopes of age-earnings profiles seems a natural way to test whether these laws encourage or discourage Lazear contracts, the test can also be derived as an implication of the theoretical model outlined above, under some conditions. First, if the predominant effect of age discrimination laws is to deter Lazear contracts, then the slopes of earnings profiles will move toward those of productivity profiles $\left(v_{t}\right)$ and hence be flatter. Alternatively, if the predominant effect of such laws is to reduce the probability that firms renege on implicit

\footnotetext{
${ }^{5}$ Even Epstein (1992), a fierce critic of the ADEA, recognizes the potential gains it might yield by reducing opportunistic behavior by employers. He asserts, however, that the costs outweigh the gains.

${ }^{6}$ If age discrimination laws increase efficiency via increasing the use of Lazear contracts, they should also result in higher present values of earnings profiles, and vice versa. However, in part because we do not have data on tenure spells, we do not focus on this empirical implication (although we present some limited evidence below).
} 
contracts, then $i$ falls (remaining above $r$, we assume). If we assume that $e$ and $q$ are constant but that $s$ rises with age, then equation (3) implies that the rate of growth of earnings rises as $i$ falls. ${ }^{7}$

We use census data to extend the empirical analysis over decades covering the passage of state age discrimination laws. Because the census has no information on tenure, we focus on age-earnings profiles rather than on tenure-earnings profiles. Since increased use of long-term incentive contracts should steepen tenure-earnings profiles and increase attachment of workers to firms, implications for tenure-earnings profiles carry over to age-earnings profiles. Also, while changes in the slopes of earnings profiles could be interpreted as arising from changes in the "terms" of implicit long-term incentive contracts, they may also reflect changes in the incidence of such contracts, which is reflected in average age-earnings profiles.

A critical identifying assumption is that age discrimination laws are not correlated with changes in the slopes of age-productivity profiles, because these changes would generate changes in age-earnings profiles even in spot labor markets. We are also careful to attempt to distinguish between changes in the slopes of earnings profiles induced by relative demand shifts toward older workers stemming from age discrimination laws and changes in life cycle earnings profiles that are induced for young cohorts entering the labor market after the passage of such laws; it is the latter that we are trying to estimate.

The key hypothesis underlying the alternative interpretation of age discrimination laws that we test is that such laws act as precommitment devices in long-term incentive contracts. However, other mechanisms, such as severance payments possibly backed by escrow accounts, could have allowed employers to tie their hands with regard to these contracts. Incentive-compatible severance schemesspecifying a payment equal to the present value of the excess of earnings over marginal product (or zero, whichever is greater) over the remaining time with the firm-could be very complicated since they would have to vary with the age (or tenure) of the worker. Thus contracting costs may have deterred the use of severance pay for at least some employers. In addition, if a severance scheme had to be backed by an escrow account, the size of the escrow account could be prohibitively large, running into capital market constraints even for large employers. For example, at the age at which pay first ex-

\footnotetext{
${ }^{7}$ When $e$ is also increasing, the result is more ambiguous since high disutility of effort in the future weighs more heavily on the no-shirk condition in earlier periods, because of the lower discount rate. However, as long as $e$ does not rise too quickly, this result still holds.
} 
ceeds marginal product; the present value of the future excess of earnings over marginal product could exceed current salary many times over if earnings profiles are steep relative to productivity profiles. While we can speculate about alternative enforcement mechanisms, ultimately the data speak to whether it is likely that age discrimination laws created or improved on precommitment devices, or instead simply replaced other devices (while perhaps imposing other costs). In particular, if adequate enforcement mechanisms existed in the absence of age discrimination laws, there should be no evidence that age discrimination laws strengthened existing longterm incentive contracts; instead, we should find either no effects or negative effects on the slopes of earnings profiles. In contrast, evidence that such laws led to steeper age-earnings profiles would imply that the effect of such laws was to strengthen such contracts and hence that, on net, age discrimination laws made precommitment more credible.

A natural issue in interpreting our evidence is the implications of other models for the effects of age discrimination laws on the steepness of age-earnings profiles. In specific human capital models, workers may be more inclined to bear the costs of investment if it becomes less likely that firms will fire them when older, leading to steeper earnings (and productivity) profiles in response to prohibitions of age discrimination. However, in the standard version of this model, firms have no incentive to discriminate against older workers since they are paid less, rather than more, than their marginal product, so this model implies no impact of age discrimination laws. In Carmichael's (1983) alternative specific human capital model, workers are paid more than their marginal product when old, but firms have no incentive to discriminate against older workers by firing them because of the existence of promotion ladders. The general human capital model allows little role for firms. Nonetheless, if simple taste-based discrimination reduces employment opportunities for older workers, then laws prohibiting such discrimination could increase investment and therefore wage growth over the life cycle. Thus, while we are confident that our empirical procedures estimate causal effects of age discrimination laws on earnings profiles, our results do not necessarily speak solely to Lazear contracts. But we regard the interpretation of the results as testing the efficiency implications of age discrimination laws that arise via effects on Lazear contracts as a compelling one because the model outlined above generates the predictions for the alternative effects of age discrimination laws that we test, as well as the incentives for employers to discriminate on the basis of age. 


\section{Age Discrimination Legislation}

Using federal legislation to estimate the effects of age discrimination laws by comparing labor market outcomes before and after passage of the ADEA risks confounding the effects of the legislation with period or cohort effects in age-earnings profiles. Instead, we rely on state-level variation in age discrimination laws created by the adoption of such laws in some states prior to the ADEA. Whereas in the federal "experiment" the control group is observations from an earlier period, the state-level variation provides a control group that includes observations on different states in the same period, eliminating the influence of period or cohort effects that are common across states. By using data from many years, we can also remove the influence of persistent differences in the dependent variables across states.

The federal ADEA was enacted in 1968 and strengthened in 1979 with the transfer of enforcement authority to the Equal Employment Opportunity Commission (EEOC) (Stacy 1990). Amendments in 1978 increased the age of mandatory retirement to 70 and prohibited nearly all forms of mandatory retirement prior to age 70; subsequent amendments essentially prohibited mandatory retirement at any age. Given the passage of federal legislation prohibiting age discrimination in 1968, identifying information from state laws comes from cross-state variation in state laws before this period. We also get identifying information from the federal ADEA because some states had legislation in place when the federal legislation passed and because some states had age discrimination laws protecting a wider age range than that covered by the initial federal law.

In some analyses we distinguish between age discrimination laws with explicit enforcement mechanisms and those with apparently weak enforcement, as alluded to in the discussion of transferring authority for enforcing the ADEA to the EEOC, although laws with weak or no explicit enforcement mechanisms may have some effect, perhaps in part because they give claimants standing in court. Distinguishing among laws in this way also yields additional identifying information from variation in state laws because we treat the federal law as operating with weak enforcement until 1979.

Table 1 documents the development of state legislation regarding age discrimination, on the basis of extensive review of the sources listed in the note to the table. ${ }^{8}$ Table 2 describes the variables used

\footnotetext{
${ }^{8}$ We do not use the laws for 1980 and beyond, but note them in table 1 for reference purposes.
} 


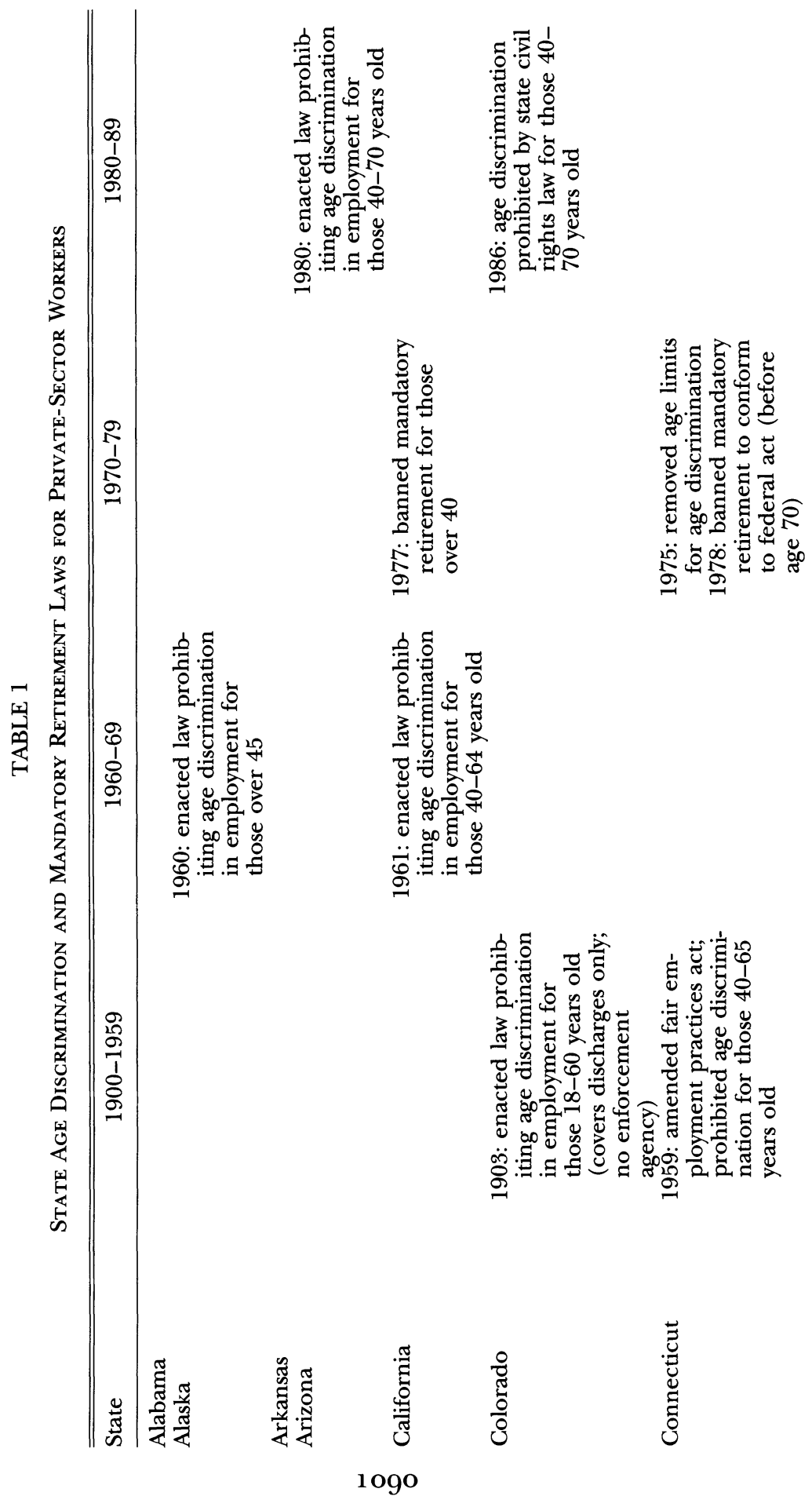



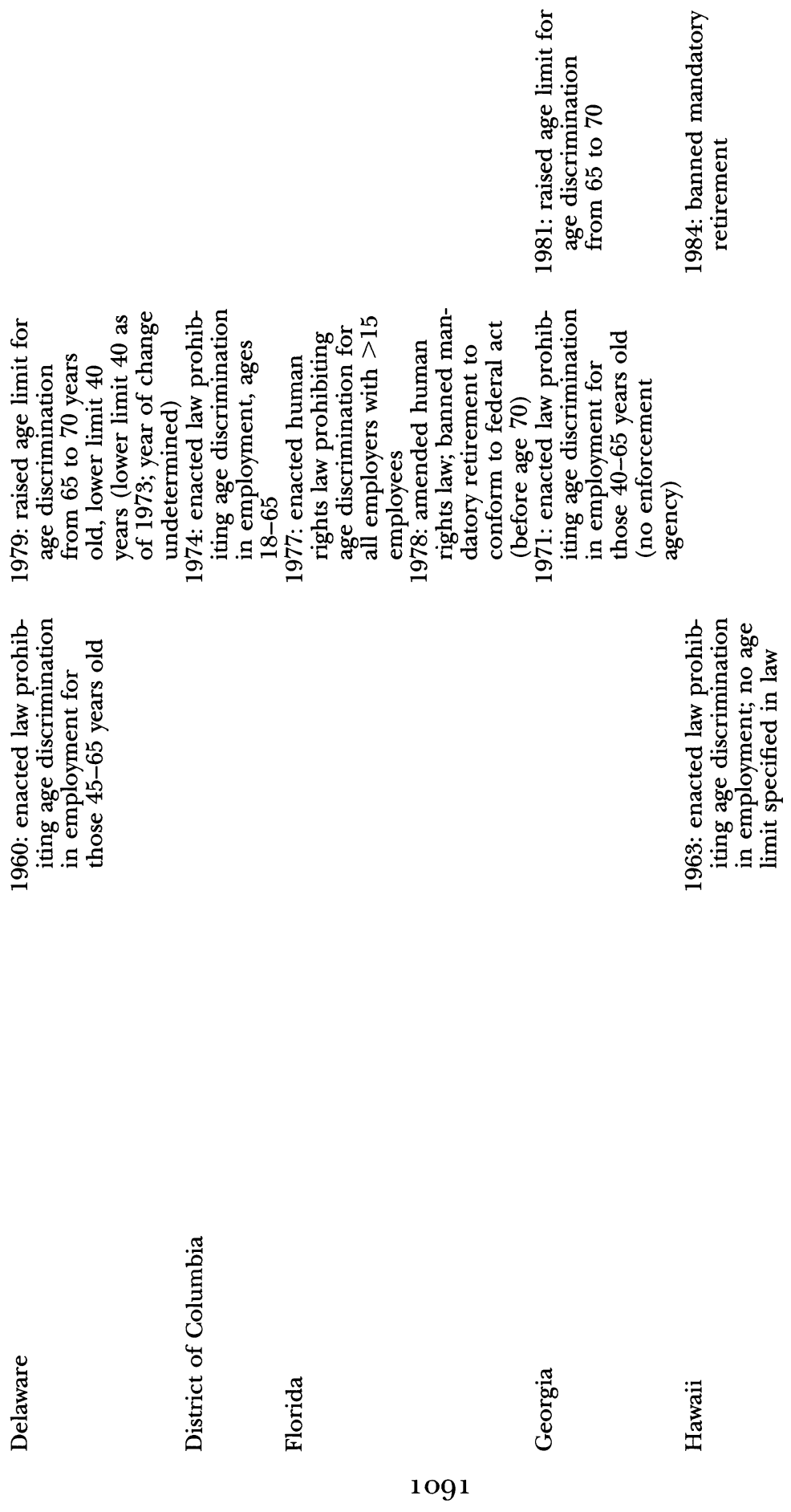


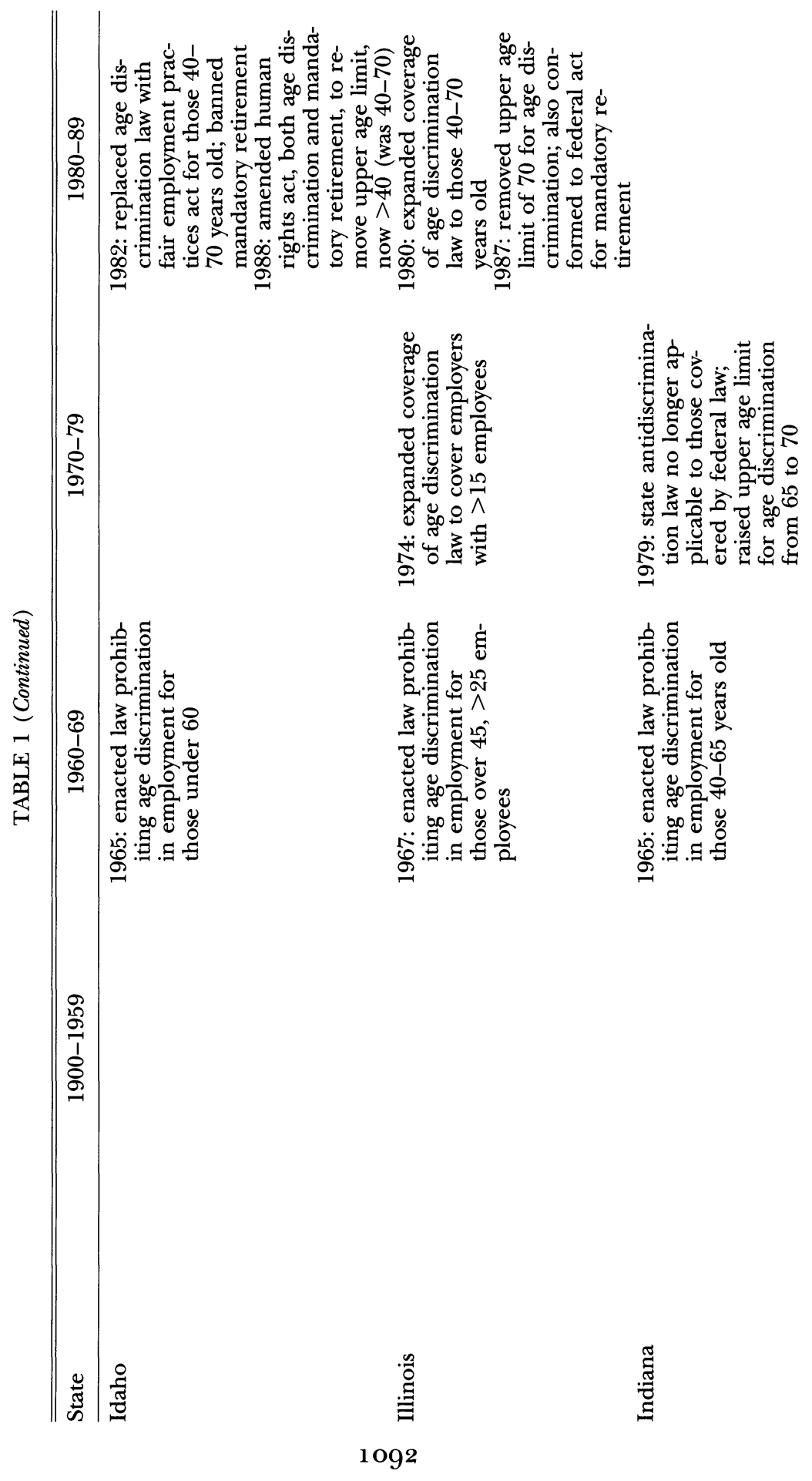




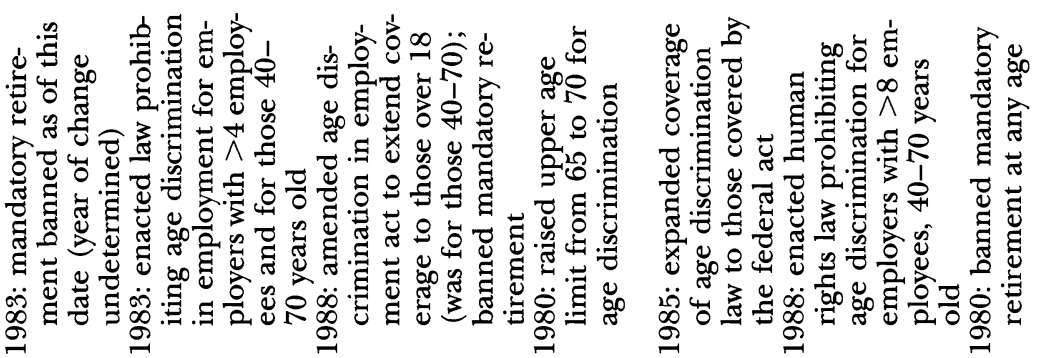
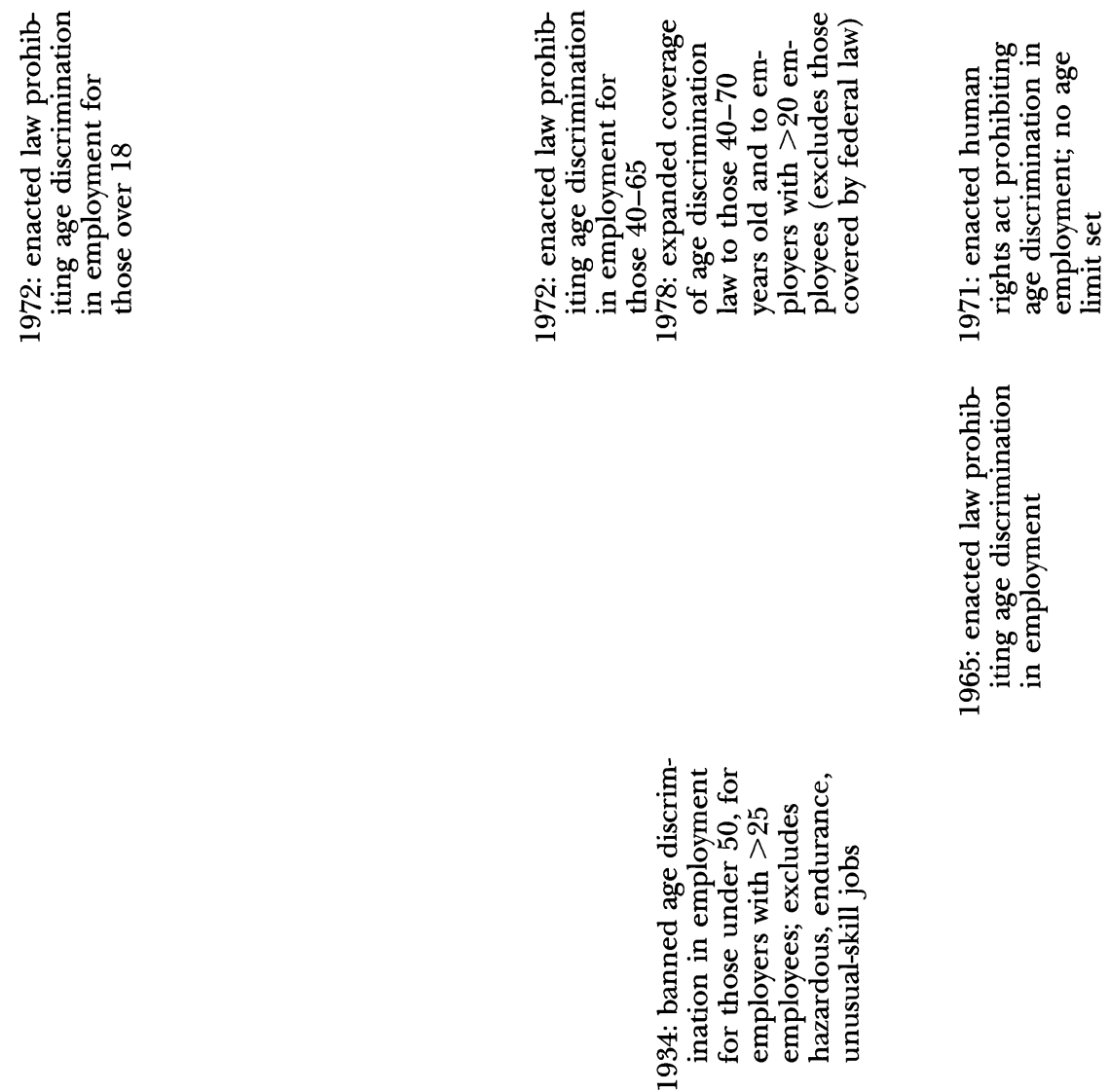

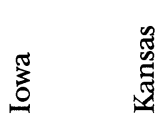

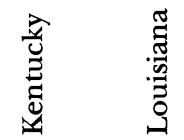

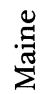




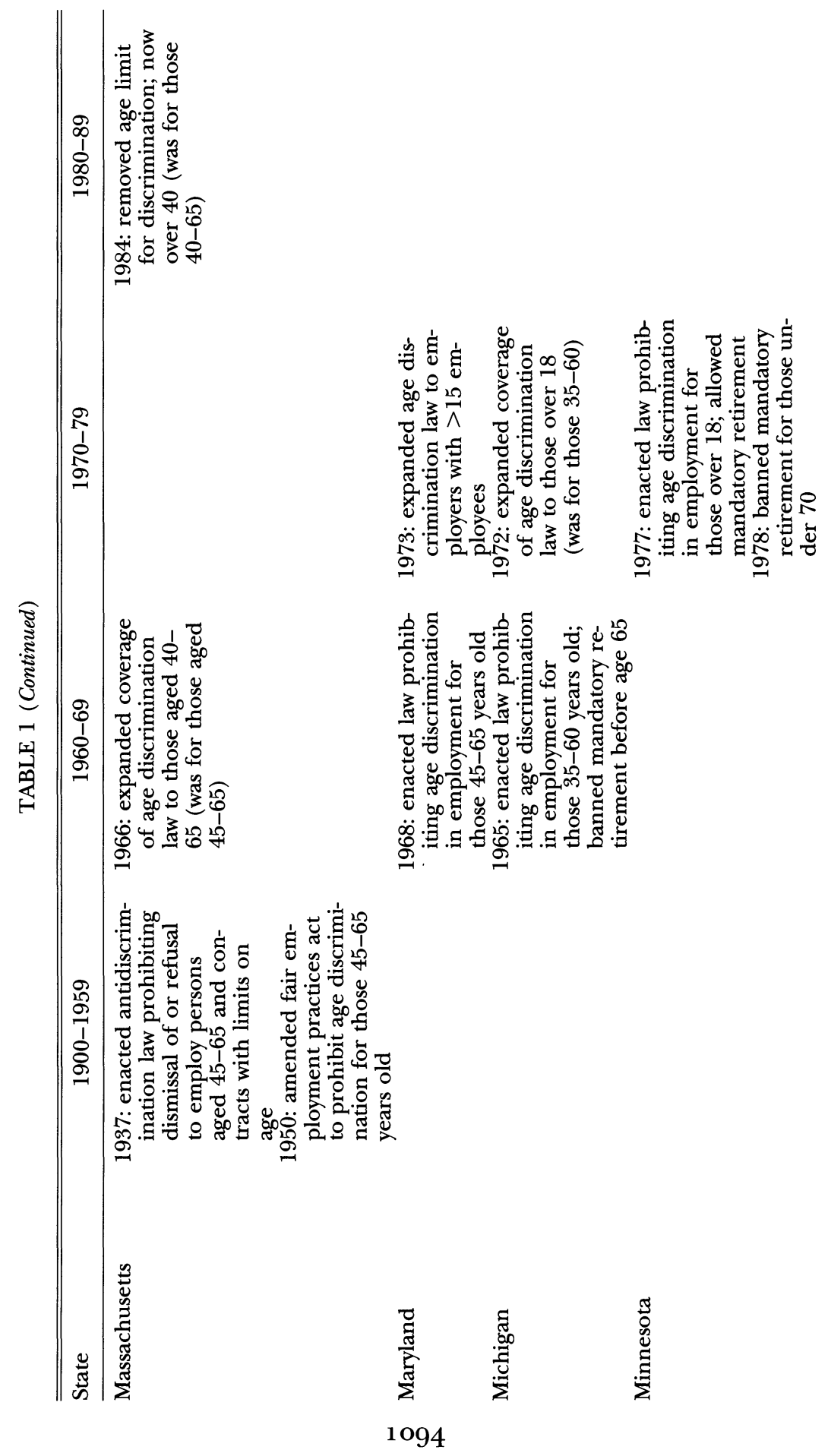



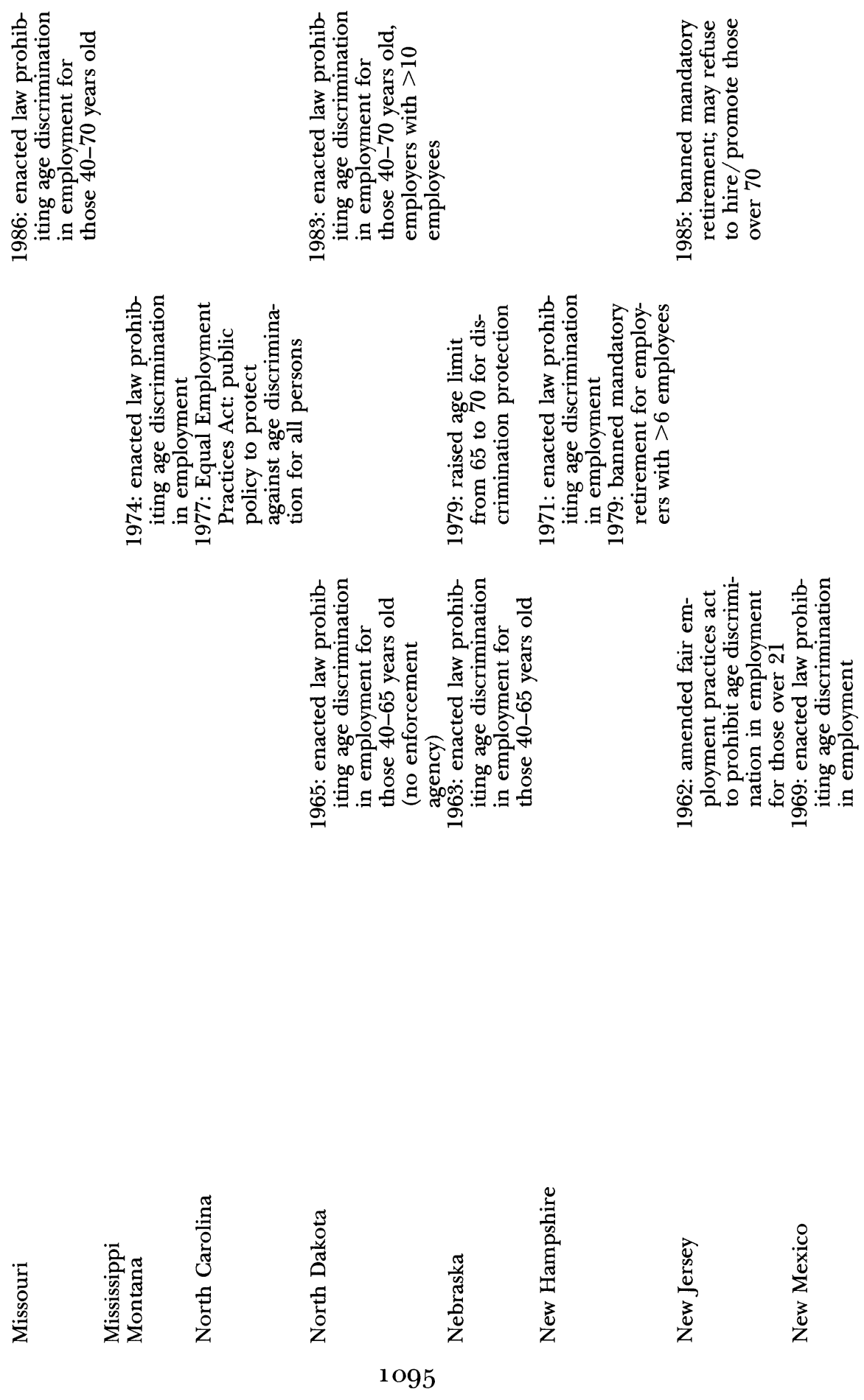


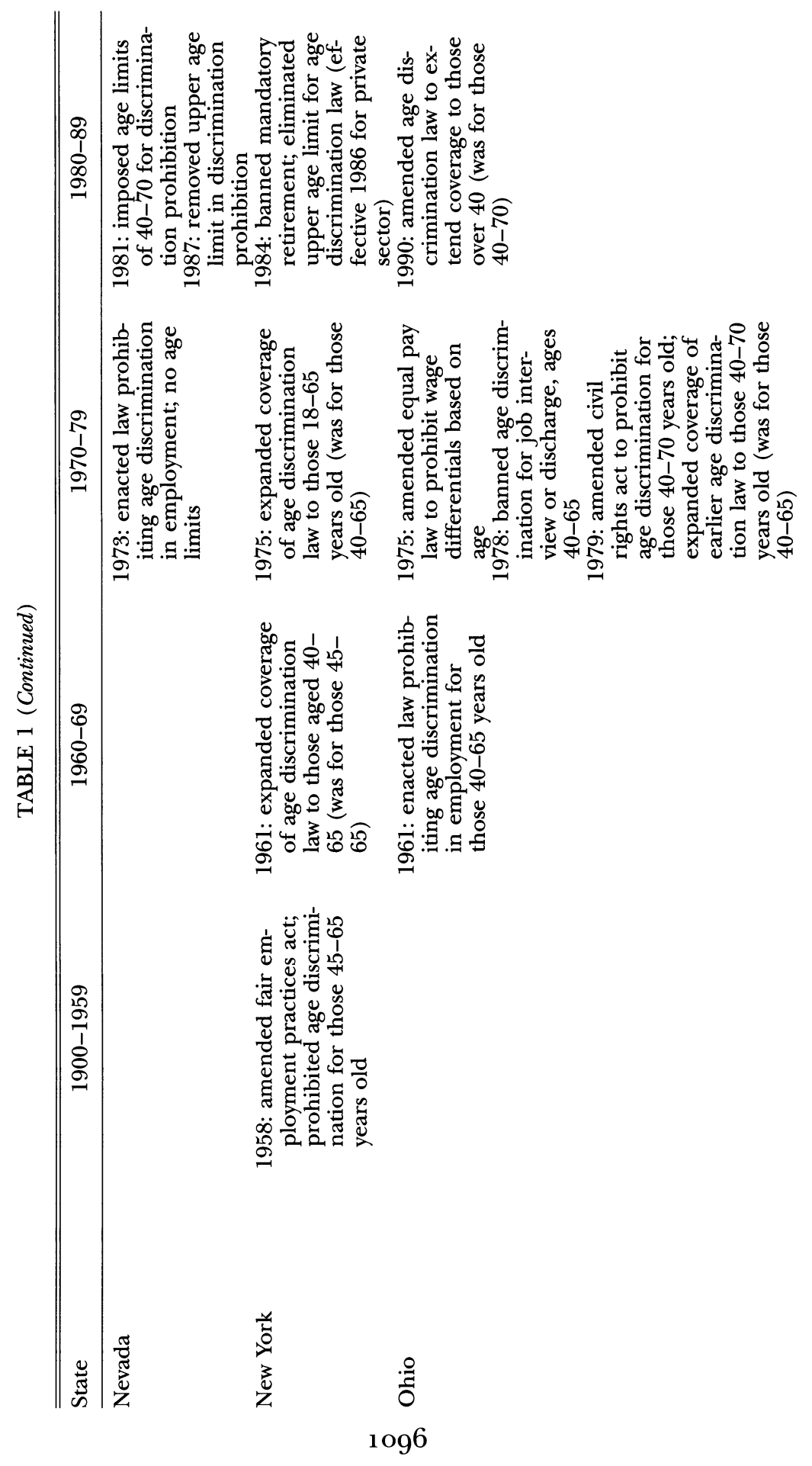



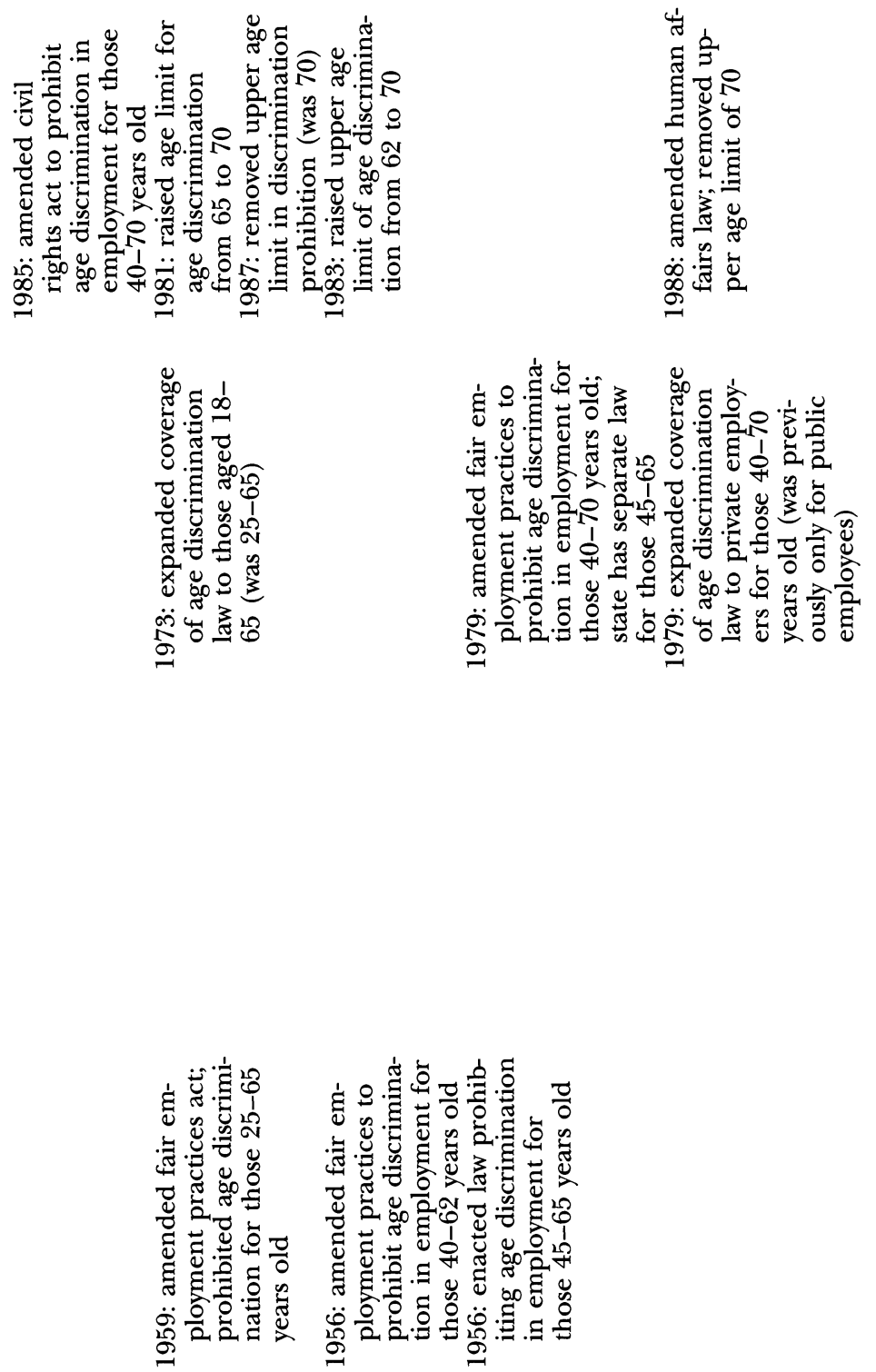

हี่

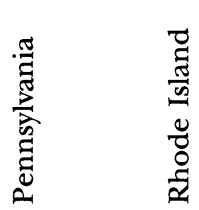

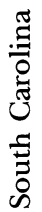

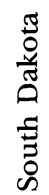

1097 


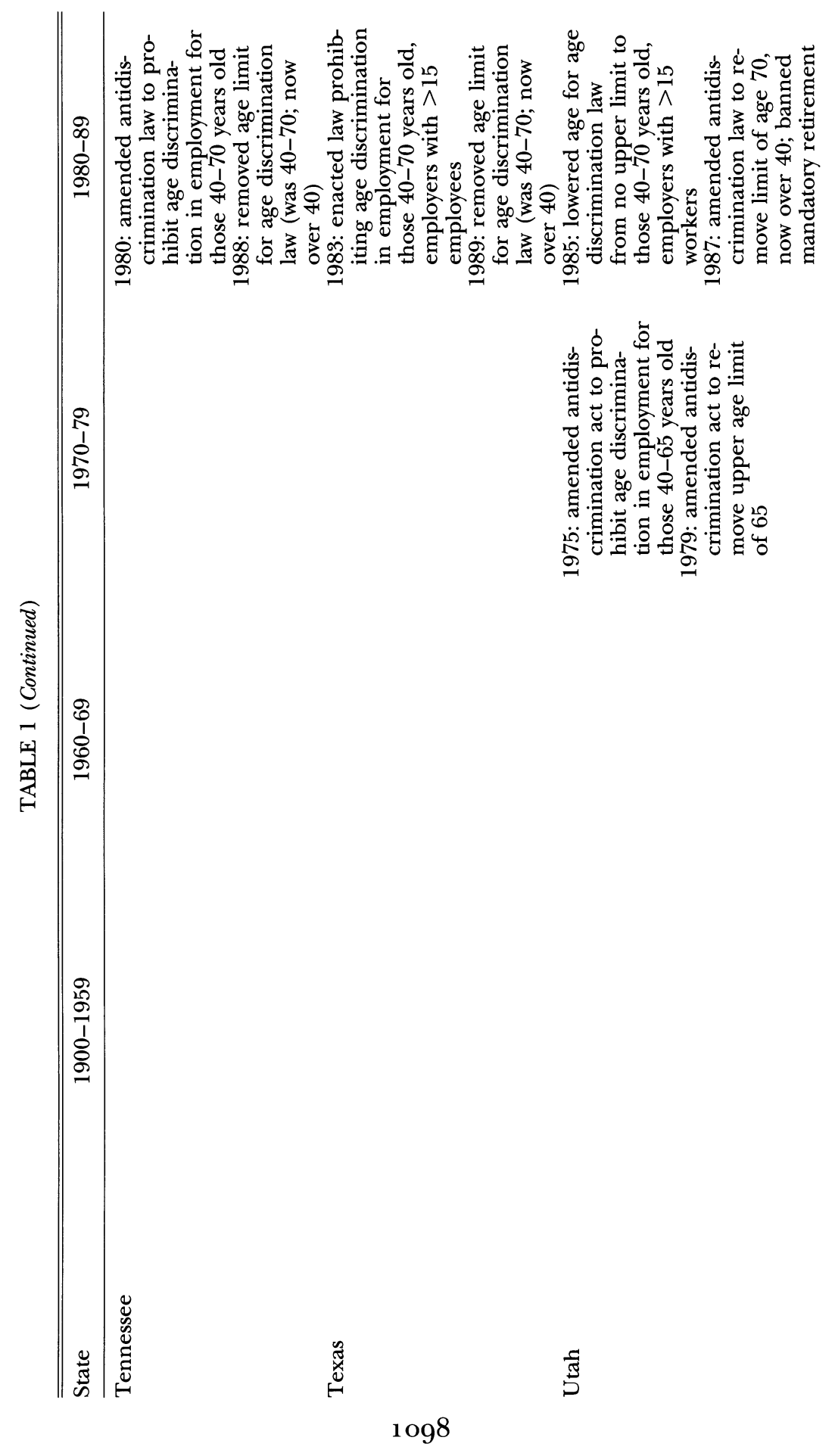




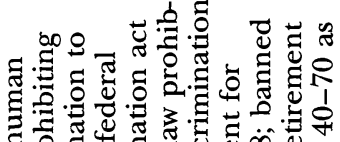
둥.

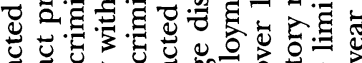
论

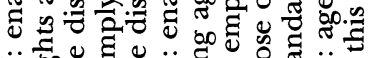

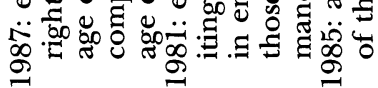
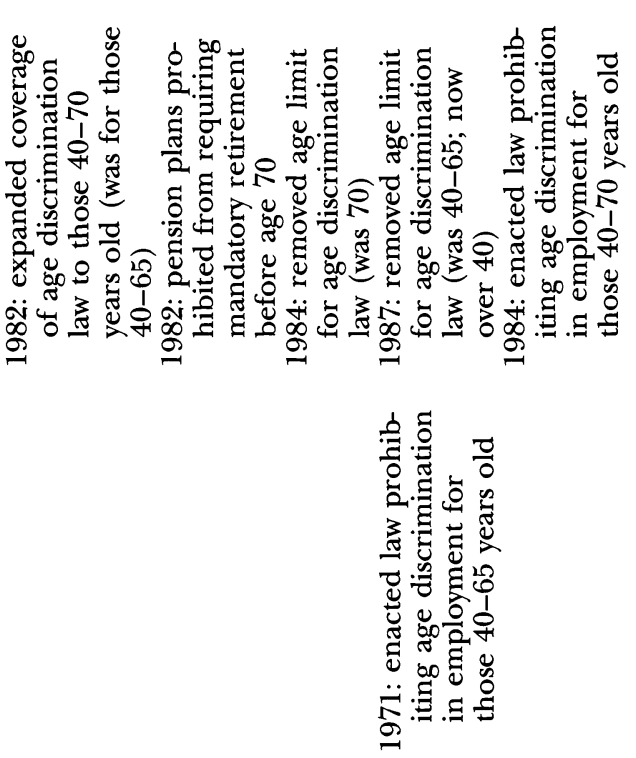
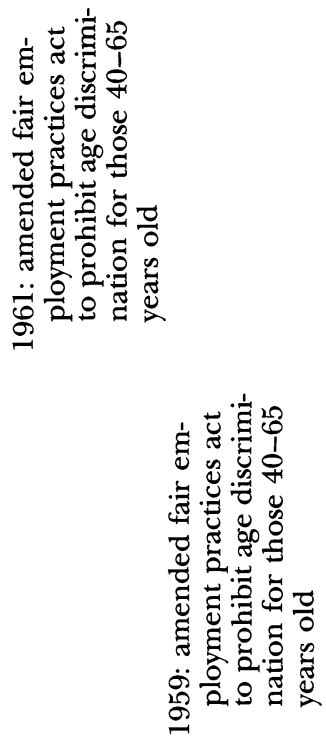

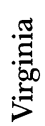
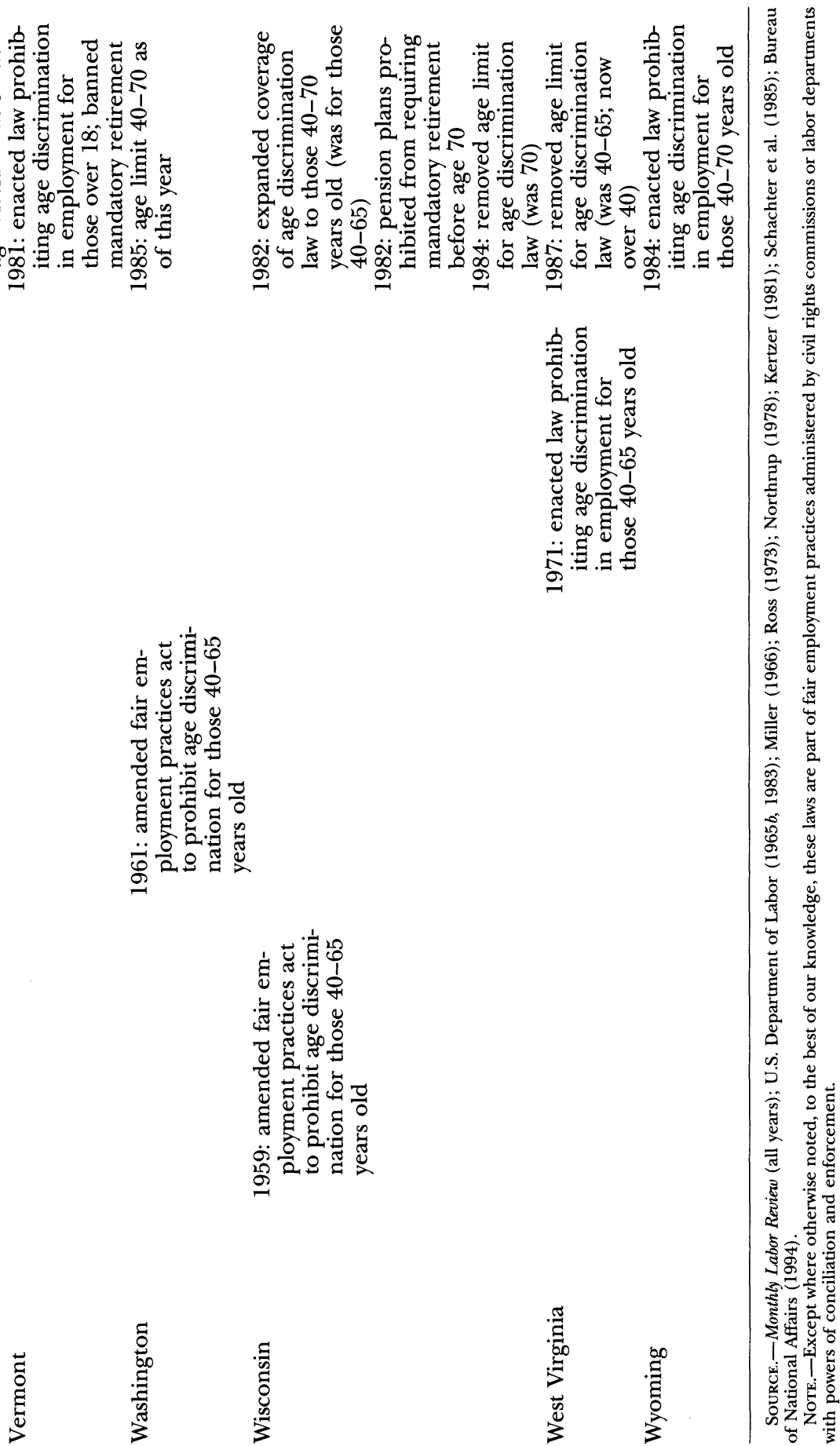


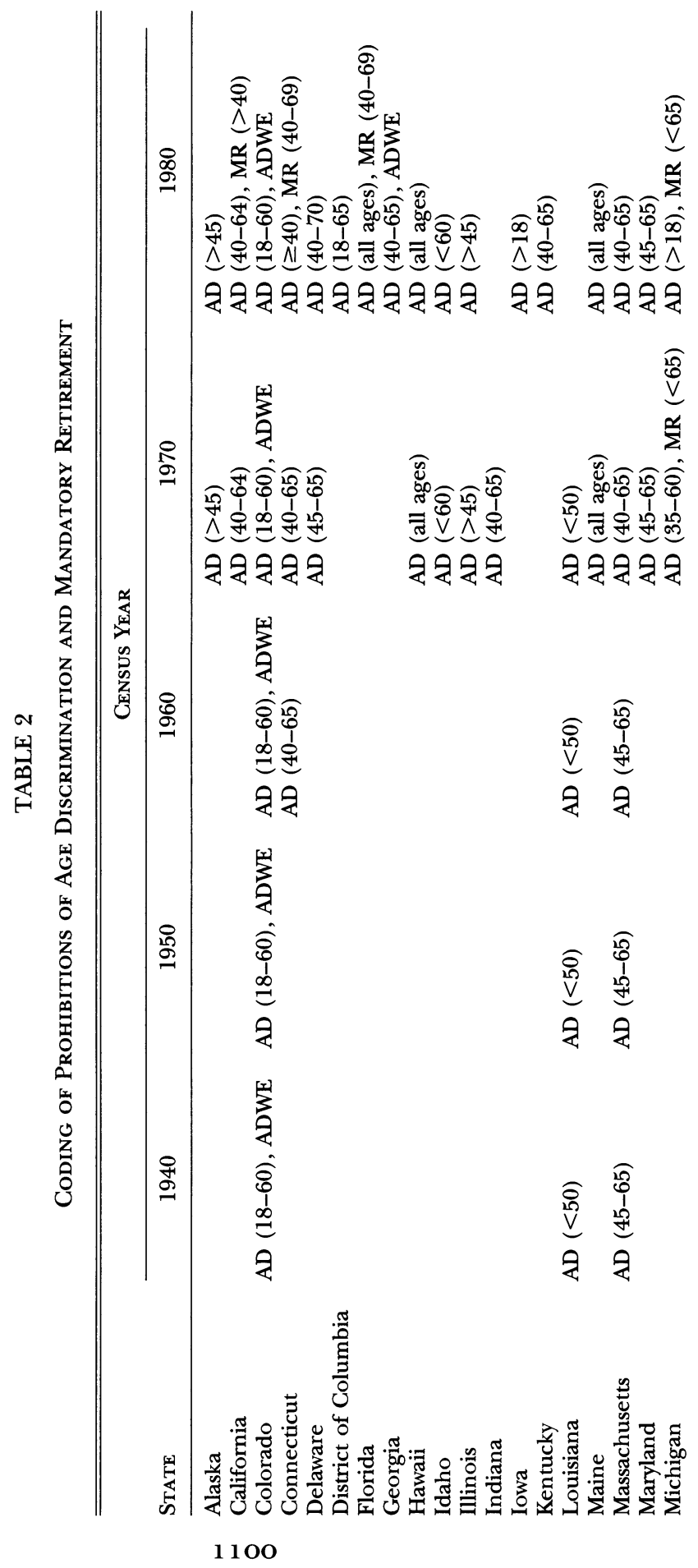




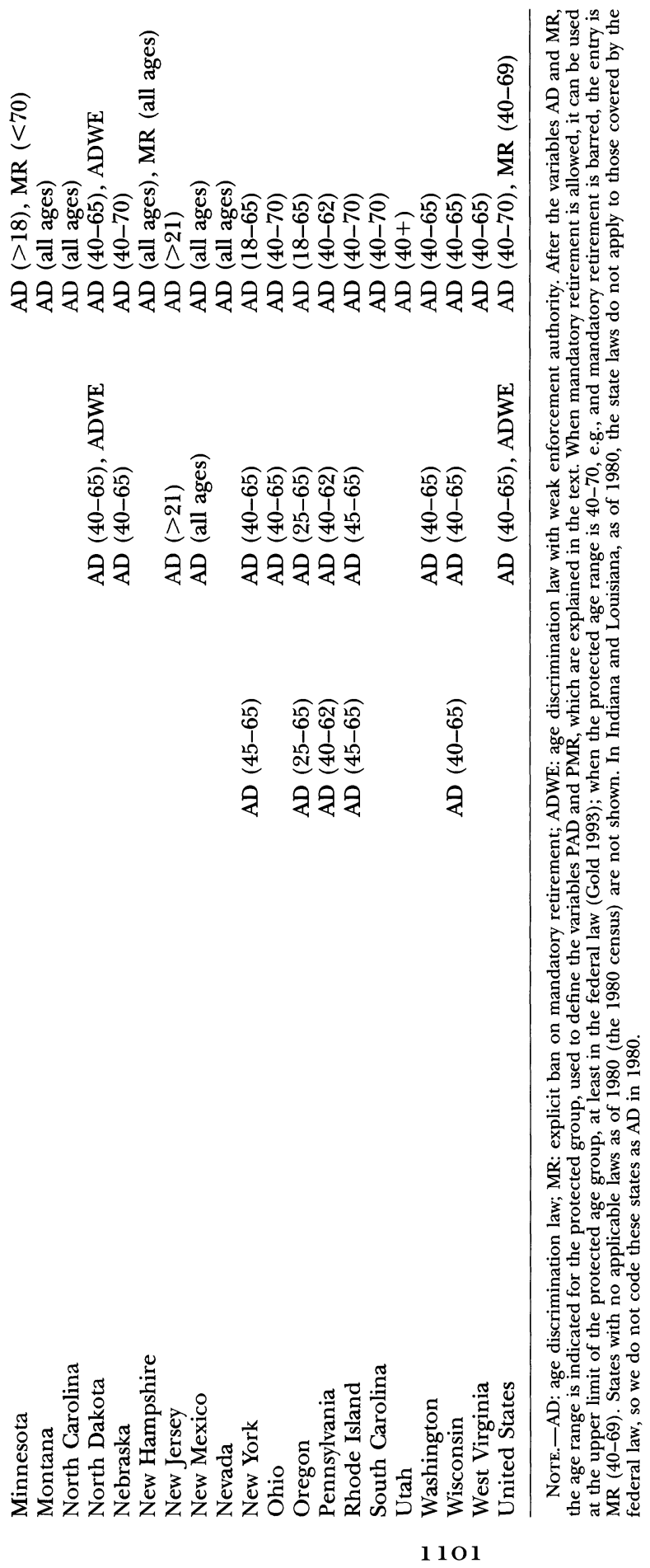


to code the state laws. Table 1 reveals numerous instances in which states passed one of two types of legislation prior to similar federal legislation. First, by 1959, some states (e.g., Colorado) passed laws prohibiting age discrimination for some specified age range, with an upper limit. By 1969, additional states (e.g., Michigan) passed such laws with upper age limits at or below that in the original ADEA. (We refer to, e.g., 1959 and 1969 because the data cover the year prior to each decennial census.) Other states (e.g., Illinois) passed laws barring age discrimination with either no upper age limit specified or an age range wider than that covered by the original ADEA. Second, by 1979, some states (e.g., California) passed laws explicitly barring mandatory retirement. In Michigan (after 1970) and Minnesota, the upper end of the age range protected by the prohibition of mandatory retirement is lower than that of the age discrimination statute, pointing out that-like the original ADEA - an age discrimination statute need not prohibit all mandatory retirement. As a consequence, in the empirical work, we examine the independent impact of mandatory retirement prohibitions. Table 1 also provides information on enforcement. Most of the state laws were part of fairemployment practices, with a civil rights commission or labor department given powers of conciliation and enforcement. ${ }^{9}$ On the other hand, in some states, generally when the laws were not part of fairemployment practices, there is no explicit enforcement authority (e.g., North Dakota's 1965 law).

Table 2 also includes a row for the federal legislation. We have included the code for weak enforcement (ADWE) for the federal law as of 1970, when the Department of Labor (rather than the EEOC) was responsible for enforcing the ADEA, and few resources were devoted to this enforcement. In addition, only as of 1980 did the federal law explicitly prohibit essentially all forms of mandatory retirement (prior to age 70). Thus, only for that year is an explicit prohibition coded.

\section{The Census Data}

We extract data from the decennial Census of Population for 1940, $1950,1960,1970$, and 1980, which we merge with our variables describing age discrimination laws by state and year. We use the 1 percent public use samples for 1940, 1950, 1960, and 1970 (using the

\footnotetext{
${ }^{9}$ Existing research documents state courts' enforcement of rulings of state civil rights commissions regarding state antidiscrimination statutes and other evidence that such laws had an impact (e.g., U.S. Department of Labor 1965a; Friedman 1984; Wendt, Slonaker, and Coleman 1993).
} 
15 percent questionnaire sample for 1970 ). For 1980 , we use a 0.5 percent sample (a subset of the A sample, which identifies all states). We restrict the sample to white males aged 18-70 working in the private sector, excluding nonwhites to avoid confounding effects of age discrimination laws with effects of laws protecting other groups. We exclude unpaid and public-sector workers (including armed forces) and self-employed workers for most of the analysis. We also exclude individuals who had missing or obviously erroneous data. For the earnings analysis, we exclude part-time workers (fewer than 27 weeks per year or 30 hours per week) since the Lazear model is probably more applicable to full-time, year-round workers. The earnings data refer to annual earnings. We define employment as whether any earnings for the previous calendar year are reported. Because hours of work refer to usual weekly hours in the census year, whereas weeks of work refer to the previous calendar year, and because these variables are coded in categories, we analyze earnings including controls for hours and weeks of work rather than attempting to construct an hourly wage.

\section{Employment Effects of Age Discrimination Legislation}

We first examine the effects of age discrimination legislation on the employment of protected workers. Although the alternative perspectives on age discrimination laws do not have different implications for employment effects, age discrimination laws are more likely to affect the formation of Lazear contracts (in either direction) if they are binding and therefore boost employment of older workers, either by reducing the use of involuntary terminations or by decreasing bonding costs. However, higher employment of older workers is sufficient but not necessary for age discrimination laws to be binding because these laws may make it more difficult for older workers who lose or leave their jobs for other reasons to find reemployment, so that the overall employment effect could go in the other direction.

We begin with the simplest version of the employment equation we estimate, ignoring the federal legislation by using only the 1940, 1950, and 1960 censuses. This equation has the form

$$
\begin{aligned}
E_{i j t}= & \mathbf{X}_{i j t} \beta+\mathbf{T}_{t} \beta^{\prime}+\mathbf{S}_{j} \beta^{\prime \prime}+\mathrm{AD}_{j t} \cdot \mathrm{PAD}_{i j t} \alpha \\
& +\mathrm{AD}_{j t} \cdot\left(1-\mathrm{PAD}_{i j t}\right) \alpha^{\prime}+\epsilon_{i j t},
\end{aligned}
$$

where $E$ is a dummy variable for employment, $\mathbf{X}$ is a vector of standard controls (including age dummy variables), $\mathbf{T}$ is a set of year dummy variables, $\mathbf{S}$ is a set of state dummy variables, and $i, j$, and $t$ 
index individuals, states, and years. To control for secular changes in age-employment profiles, in some specifications we also interact the age profile with year dummy variables. Additional controls added in some specifications are discussed below.

The variable $A D$ is the indicator for an age discrimination law; $\mathrm{PAD}$ is a dummy variable equal to one when the individual is in the age range indicated in the parentheses in table 2. The interactions of $\mathrm{AD}$ and PAD pick up the effects of the laws on the "protected" groups. Because these laws could also affect unprotected groups of workers in the same state, the interaction with 1 - PAD is also included in equation (5). Age discrimination laws could lead employers to substitute away from younger workers as they hire or retain more older workers. Alternatively, they may increase employment of younger workers because of increased costs of employing older workers, or they may generate general employment increases from higher lifetime productivity. Regardless, unprotected workers do not necessarily serve as a valid control group. Instead, we make comparisons between workers in states with age discrimination laws and similar workers in states without such laws.

In equation (5), $\alpha$ is the effect of a ban on age discrimination. We present estimates of this equation, excluding the state dummy variables and age-year interactions, and using the state laws and census data for the years 1940-60 in column 1 of table 3. Given the huge sample, we present ordinary least squares (OLS) estimates of a linear probability model. ${ }^{10}$ The estimate of $\alpha$ is positive (and significant), indicating that age discrimination laws boost the employment rate of protected workers by .016 . The estimate of $\alpha^{\prime}$ is negative, suggesting that such laws, on net, slightly lower the employment rate of unprotected workers.

Next, we augment the specification to allow age discrimination laws to have a greater effect on the oldest workers in the protected group, defining a dummy variable OLD for workers 60 or older:

$$
\begin{aligned}
E_{i j t}= & \mathbf{X}_{i j t} \beta+\mathbf{T}_{t} \beta^{\prime}+\mathbf{S}_{j} \beta^{\prime \prime}+\mathrm{AD}_{j t} \cdot \mathrm{PAD}_{i j t} \cdot \mathrm{OLD}_{i j t} \alpha \\
& +\mathrm{AD}_{j t} \cdot \mathrm{PAD}_{i j t} \cdot\left(1-\mathrm{OLD}_{i j t}\right) \alpha^{\prime} \\
& +\mathrm{AD}_{j t} \cdot\left(1-\mathrm{PAD}_{i j t}\right) \alpha^{\prime \prime}+\epsilon_{i j t} .
\end{aligned}
$$

The results, reported in column 2, indicate stronger effects of age discrimination laws on the employment of the oldest protected workers, boosting employment of protected workers aged 60 and over by

\footnotetext{
${ }^{10}$ Given memory constraints arising from the large sample and large number of variables, we had to build up moment matrices prior to computing estimates, precluding estimation of nonlinear models.
} 


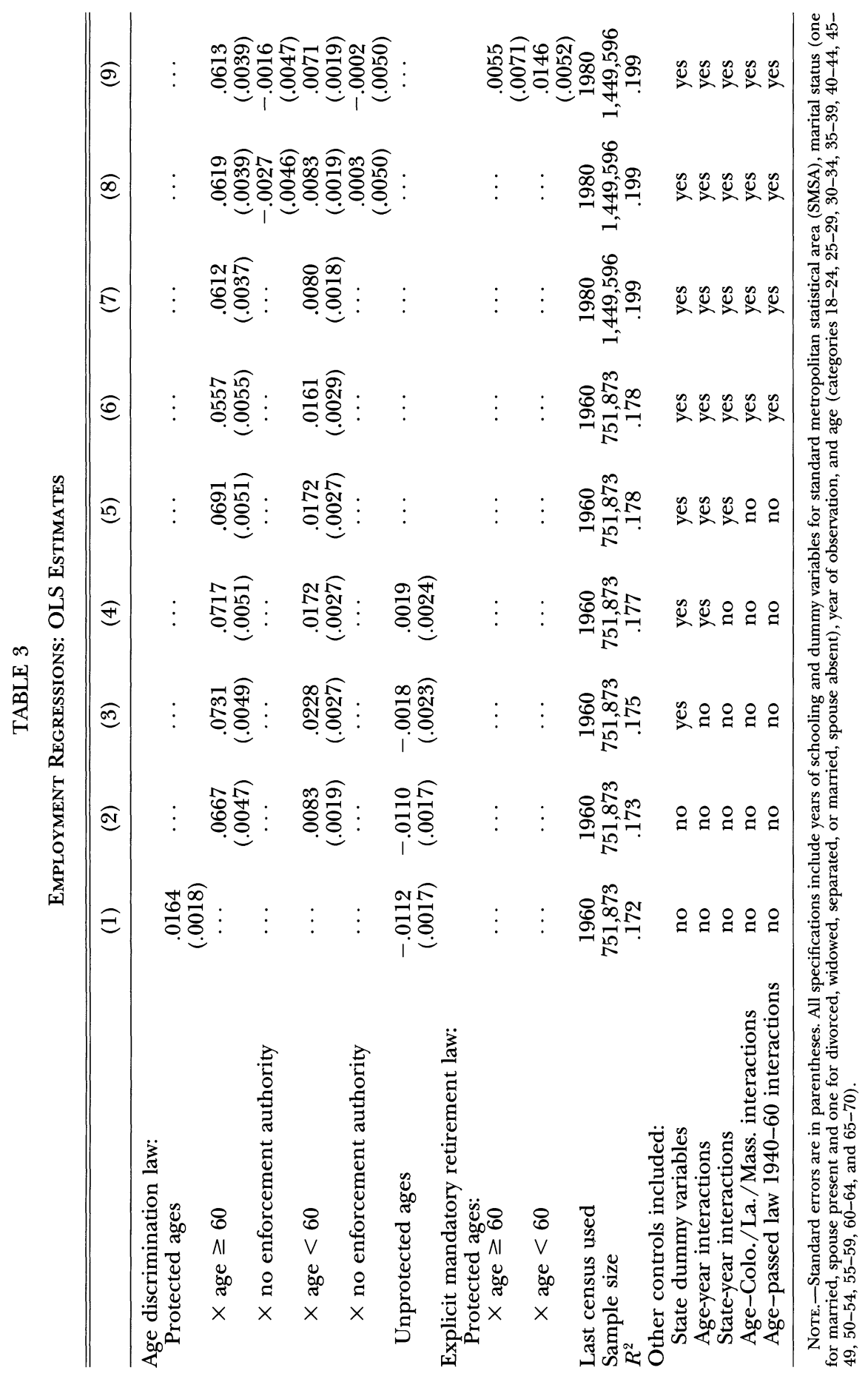


.067 , with only a slight positive effect on protected workers under age 60 .

In column 3 we add state dummy variables, which results in slightly larger positive employment effects on protected workers, for both those aged 60 and over and those under age 60 . In addition, the negative effect of such laws on the employment of unprotected workers becomes small and insignificant. In column 4 we introduce interactions between the age dummy variables and the year dummy variables, allowing the age-employment profiles to vary by year. In this specification we identify the effects of age discrimination from differences within years in employment of workers in different age groups, between states that did and did not ban age discrimination. The results indicate slightly weaker effects of such laws in boosting employment of protected workers, with employment rates higher by .072 for those aged 60 and over and .017 for those under age 60 . The estimated effect on unprotected workers is now positive but still very small and insignificant. Thus, to this point, age discrimination laws appear to boost employment of older, protected workers without inducing substitution away from younger, unprotected workers.

Because there may be common error components for observations in the same state and year that are not persistent across states or across years, the residuals in these specifications may be dependent within states and years, biasing the standard errors downward. To address this, we add state-year interactions to the specification. This fixed-effects specification is more flexible than random effects (Moulton 1986) because it allows us to purge the estimates of bias arising from a correlation between the state-year effects and the observables, such as might arise from economic shocks that affect all workers in the state. Note that once we include state-year interactions, it is not possible to identify $\alpha^{\prime}$ in equation (5) (and the corresponding parameters in the other employment equations we estimate) because an intercept shift for all workers in a state and year is absorbed in the state-year interactions; but we still identify the relative shift for older subgroups of workers. In the estimates incorporating state-year effects, reported in column 5, the effects of age discrimination laws on protected workers are virtually unchanged.

In columns 1-5, identification of the effects of age discrimination laws comes from states that enacted such laws in 1950 or 1960, as well as from states that already had them as of 1940 (Colorado, Louisiana, and Massachusetts). Because we do not get a before and after comparison from these three states, it might be preferable to identify the effects of age discrimination laws only from the states whose laws changed over the 1940-60 period. We do this by allowing a separate age-employment profile for these three states. We also take this anal- 
ysis one step further, allowing for differences in the shape of the age-employment profile in the set of states that passed age discrimination laws in the 1940-60 period, by introducing interactions between the age dummy variables and a dummy variable for this set of states. This is equivalent to a difference-in-difference estimator allowing a fixed effect in the slope of the age-employment profile that differs between states that did and did not pass age discrimination laws prior to the federal legislation. The results are reported in column 6. The estimated coefficients of the age discrimination variables decline slightly, but the qualitative conclusions are unchanged.

We next consider two additional features of age discrimination legislation. First, we incorporate changes in federal legislation. As of 1970, the federal ADEA protected workers aged 40-65, and as of 1980 , workers aged 40-70. Thus we can use data from the 1970 and 1980 censuses as well, defining PAD on the basis of the age range encompassed by federal and state laws. The implicit assumption is that the effects of federal and state laws are the same, so that, for example, when the federal law is passed, it supersedes state law. However, the existence of a separate state law may give individuals additional options for pursuing age discrimination claims and thus result in stronger effects of the law. A state law may also cover some workers not covered by federal law, such as workers in small firms. On the other hand, federal legislation may have stronger effects. Unfortunately, we cannot test for different effects of state and federal laws since the separate variables for the federal law would be perfectly collinear with year dummy variables or the age-year interactions. All we can do is estimate the average effects of the federal and state laws, which we can compare with the estimated effects of state laws through 1960.

Second, as noted earlier, a few states passed age discrimination laws with weaker enforcement, and the federal law could be viewed similarly until 1979. We therefore estimate an augmented specification that allows for differential effects of age discrimination laws with weaker enforcement:

$$
\begin{aligned}
E_{i j t}= & \mathbf{X}_{i j t} \beta+\mathbf{T}_{t} \beta^{\prime}+\mathbf{S}_{j} \beta^{\prime \prime}+\mathrm{AD}_{j t} \cdot \mathrm{PAD}_{i j t} \cdot \mathrm{OLD}_{i j t} \alpha \\
& +\mathrm{AD}_{j t} \cdot \mathrm{PAD}_{i j t} \cdot\left(1-\mathrm{OLD}_{i j t}\right) \alpha^{\prime} \\
& +\mathrm{AD}_{j t} \cdot \mathrm{PAD}_{i j t} \cdot \mathrm{OLD}_{i j t} \cdot \mathrm{ADWE}_{j t} \gamma \\
& +\mathrm{AD}_{j t} \cdot \mathrm{PAD}_{i j t} \cdot\left(1-\mathrm{OLD}_{i j t}\right) \cdot \mathrm{ADWE}_{j t} \gamma^{\prime}+\epsilon_{i j t} .
\end{aligned}
$$

The estimates of $\gamma$ and $\gamma^{\prime}$ detect any differences in the effects of laws with weaker enforcement. North Dakota and Georgia, which had 
laws with weaker enforcement, provide no identifying information because their laws coincide with the federal law. However, the 1970 versus 1980 contrast in the federal law provides such information since numerous states had laws with explicit enforcement mechanisms as of 1970. In addition, the contrast between 1970 and earlier years provides identifying information since the federal law as of 1970 introduces states (in addition to Colorado) with age discrimination laws but weak enforcement.

Results incorporating the federal legislation are reported in column 7, where we treat the federal law as effective in 1970, without regard to enforcement. The estimates indicate a somewhat stronger (.061), statistically significant positive effect of age discrimination laws in boosting employment of the oldest protected workers and a smaller positive (.008) and significant effect on protected workers under age 60. Alternatively, column 8 reports estimates of equation (7), incorporating information on enforcement. The estimated overall employment effects are very similar. The point estimate indicates that employment of the oldest protected workers is boosted by a bit less in states with weak enforcement, although this differential is not statistically significant. In general, the similarity of the estimated effects of state and federal laws indicates not only that state antidiscrimination laws are far from irrelevant, but that we can treat federal and state age discrimination laws nearly symmetrically.

Finally, prohibitions on age discrimination do not always include explicit prohibitions of mandatory retirement. Such explicit prohibitions may have additional effects, for example, by ruling out specific circumstances under which mandatory retirement is allowed even for workers in the protected age group (such as in the original ADEA). Table 2 reveals that we have a small amount of identifying information regarding explicit prohibitions of mandatory retirement. Michigan had such a prohibition in 1970, before the federal law included essentially a blanket prohibition of mandatory retirement. By 1980, five states had such prohibitions; but the federal legislation also became effective for workers through age 69 by 1980, so only those states with prohibitions covering a wider age range than the federal legislation provide additional information. Of these, California's law has no upper age limit; but because we look at employment effects on individuals through age 70 (presuming that we have insufficient observations to learn anything reliable about workers older than this), California adds identifying information only for 70year-olds. New Hampshire has a prohibition covering all ages, but such a prohibition is meaningless for workers under age 40; thus this state provides useful information only on 70-year-olds. Nonetheless, exploiting the limited identifying information available, we augment 
the specification in a fashion parallel to equation (7). Specifically, we define a dummy variable PMR equal to one for those in the age range covered by a mandatory retirement prohibition and add the two interaction variables MR - PMR - OLD and MR - PMR - (1 OLD). The coefficients of these variables capture the incremental effects of explicit prohibitions of mandatory retirement on older and younger protected workers.

The results are reported in column 9. The estimated effects of explicit mandatory retirement provisions are positive for both protected older and younger workers, although slightly bigger, and significant, for the younger group. Adding the mandatory retirement controls in column 9 has essentially no impact on the estimated effects of age discrimination laws. Although based on limited information on mandatory retirement, this evidence bolsters the findings discussed earlier that mandatory retirement appears to have had little effect on retirement and strengthens the hypothesis that the more general prohibition of age discrimination may be the more consequential aspect of age discrimination laws.

\section{Effects of Age Discrimination Legislation on Long-Term Contracting}

We now turn to the effects of age discrimination laws on the formation and use of Lazear contracts. As explained in Section III, if these laws encourage the formation of Lazear contracts, they should lead to steeper average earnings profiles, and vice versa. In contrast to the employment regressions, we are now interested in drawing inferences regarding the effects of age discrimination legislation on the slopes of earnings profiles. We therefore estimate equations of the form

$$
\begin{aligned}
Y_{i j t}= & \mathbf{Z}_{i j t} \beta+\mathbf{T}_{t} \beta^{\prime}+\mathbf{S}_{j} \beta^{\prime \prime}+\mathrm{PAD}_{i j t} \cdot \mathrm{AD}_{j t} \gamma \\
& +\left(1-\mathrm{PAD}_{i j t}\right) \cdot \mathrm{AD}_{j t} \gamma^{\prime}+\mathrm{AGE}_{i j t} \cdot \mathrm{PAD}_{i j t} \cdot \mathrm{AD}_{j t} \alpha \\
& +\mathrm{AGE}_{i j t} \cdot\left(1-\mathrm{PAD}_{i j t}\right) \cdot \mathrm{AD}_{j t} \alpha^{\prime}+\epsilon_{i j t},
\end{aligned}
$$

where $Y$ is log earnings. For brevity, we report estimates from a specification that uses information only on laws with explicit enforcement, assigning to the control group observations from states and years with laws that did not include an explicit enforcement mechanism; the results were very similar when we defined $A D$ on the basis of all laws without regard to enforcement.

We are trying to infer the effects of age discrimination laws on long-term incentive contracts by examining the consequences of the passage of these laws for the steepness of age-earnings profiles. How- 
ever, age discrimination laws can also affect relative demands for and hence relative wages of workers of different ages, raising an identification problem. We take two approaches to distinguishing between relative demand influences and effects on long-term contracting. First, in equation (8) we include interactions of $\mathrm{AD}$, the dummy variable indicating age discrimination legislation, with $\mathrm{PAD}$ and $1-\mathrm{PAD}$. These interactions pick up shifts in wages or earnings that are common across workers of all ages within either the protected or the unprotected age groups. Thus one identifying assumption we can make in this specification is that relative demand shifts affect equally the wages of all workers within either the protected or unprotected group. In this case, the effects on long-term contracting are reflected in changes in the steepness of profiles within each of these groups. In particular, the coefficients $\alpha$ and $\alpha^{\prime}$ on the interactions between AGE (a linear age variable), $\mathrm{AD}$, and $\mathrm{PAD}$ or 1 - PAD pick up the effects of the policies on the steepness of ageearnings profiles that arise other than through the overall differences between older protected workers and younger unprotected workers. Note that given the assumption that $\gamma$ and $\gamma^{\prime}$ pick up relative demand shifts, we cannot infer the effects that age discrimination laws have on the intercepts of age-earnings profiles, which might be of interest. ${ }^{11}$ Below, we describe a second method of isolating relative demand shifts from changes in long-term contracting that permits us to identify the effects of age discrimination laws on the slopes and the intercepts of age-earnings profiles.

In our view, we obtain more compelling evidence from equation (8) regarding the effects of age discrimination legislation on earnings profiles from the generally younger unprotected group (i.e., from the estimate of $\alpha^{\prime}$ ), for two reasons. First, as explained below, most of our identifying information for the effects of age discrimination legislation on the slopes of age-earning profiles pertains to younger workers. Second, age discrimination legislation provides protection within the class of protected workers, not just relative to unprotected workers. That is, employers can be found guilty of discrimination if they discriminate on the basis of age within the protected age group of older workers. Thus the legislation may induce relative demand shifts toward older workers within the protected age group, in which case it will be difficult to distinguish effects of these demand shifts from effects on long-term contracting.

There is an additional complication in estimating equation

${ }^{11}$ Also, only a relative change in the intercepts (e.g., only $\gamma^{\prime}$ ) is identified when we include state-year interactions, when we use what we later term the "restricted control group." 
because the potential effects of age discrimination laws on Lazear contracts are likely to appear initially only for young cohorts, for whom these contracts are formed under the new legal regime, and then to appear for older workers only as these younger cohorts age. Other effects may appear for workers who are older and are already in the labor market when age discrimination laws are passed, but these effects are less likely to reflect changes in long-term contracting. By stringing together the decennial censuses, we are able to observe random samples from cohorts as they age and to draw inferences from differences between cohorts that enter before and after age discrimination laws are enacted. In the employment specifications, the "treatment" variable $\mathrm{AD}$ was defined on the basis of whether the state in which a person resides had laws barring age discrimination in the year in which that person is observed. In studying earnings profiles, in contrast, to identify effects from those who enter after age discrimination laws pass, we instead define the treatment variables on the basis of whether the state of residence had an age discrimination law as of the year in which a person was in the youngest age group (i.e., as of the period in which they entered the labor market). The effects of age discrimination laws are then identified from changes in cohort earnings profiles that occur with the passage of age discrimination laws rather than from period effects in cross-section age-earnings profiles. For example, if a state first prohibits age discrimination in 1960, we define $\mathrm{AD}$ to equal one for workers aged 18-24 in 1960, for workers aged 18-24 and 25-34 in 1970 (because workers aged 25-34 in 1970 were all aged 24 and under in 1960), and for workers aged 18-24, 25-34, and 35-44 in 1980. In order to carry out this strategy, the cleanest approach is to exclude from the sample (and hence from the control group) observations on those workers who were in older cohorts when age discrimination laws were passed, in the years subsequent to passage of the laws, because older workers may be affected by such laws, although not in the same way as young workers coming into the labor market under a new legal regime; this yields what we term the "restricted control group."

Because they are rather complicated, table 4 details the sources of identifying information in this estimation. Included in the restricted control group are all observations from states prior to passage of age discrimination laws, which are all observations through 1960 in states without state laws. Included in the "treatment group" are all workers who were in the youngest age group (18-24) at the time the age discrimination legislation was passed. For the states that had no law and were first affected by the federal law, this includes observations on 18-24-year-olds in 1980. For the six states that passed laws in 
TABLE 4

IDENTIFYING INFORMATION FOR WAGE Profile Regressions

\section{Restricted Control Group}

Treatment group: Workers under age 25 as of census year when legislation with enforcement passed, in state under jurisdiction of legislation

Control group: All workers prior to passage of legislation with enforcement in their state (or federal legislation)

La., Mass. (passed legislation as of 1940, after 1930):

Treatment: age 18-24 in 1940, 18-34 in 1950, 18-44 in 1960, 18-54 in 1970 , and $18-64$ in 1980

Control: none

Age ranges of $\alpha$ and $\alpha^{\prime}$ identified by treatment group: age 18-54

Conn., N.Y., Ore., Pa., R.I., Wisc. (passed legislation as of 1960):

Treatment: age 18-24 in 1960, 18-34 in 1970, and 18-44 in 1980

Control: all ages prior to 1960

Age ranges of $\alpha$ and $\alpha^{\prime}$ identified by treatment group: age 18-34

States passing legislation with enforcement as of 1970:

Treatment: age 18-24 in 1970 and 18-34 in 1980

Control: all ages prior to 1970

Age ranges of $\alpha$ and $\alpha^{\prime}$ identified by treatment group: age 18-24

All other states (affected by federal legislation in 1980):

Treatment: age 18-24 in 1980

Control: all ages prior to 1980

Age ranges of $\alpha$ and $\alpha^{\prime}$ identified by treatment group: none

Broader Control Group

Treatment group: Workers under age 25 as of census year when legislation with enforcement passed, in state under jurisdiction of legislation

Control group: All workers prior to passage of legislation with enforcement in their state (or federal legislation), and workers aged 25 and over as of census year when legislation passed, in state under jurisdiction of legislation

La., Mass. (passed legislation as of 1940, after 1930):

Treatment: age $18-24$ in $1940,18-34$ in $1950,18-44$ in $1960,18-54$ in 1970 , and $18-64$ in 1980

Control: age 25 and up in 1940, 35 and up in 1950, 45 and up in 1960, 55 and up in 1960, and 65 and up in 1970

Age ranges of $\alpha$ and $\alpha^{\prime}$ identified by treatment group: age 18-64

Conn., N.Y., Ore., Pa., R.I., Wisc. (passed legislation as of 1960):

Treatment: age 18-24 in 1960, 18-34 in 1970, and 18-44 in 1980

Control: all ages prior to 1960, 25 and up in 1960, 35 and up in 1970, and 45 and up in 1980

Age ranges of $\alpha$ and $\alpha^{\prime}$ identified by treatment group: age 18-44

States passing legislation with enforcement as of 1970:

Treatment: age 18-24 in 1970 and 18-34 in 1980

Control: all ages prior to 1970 , age 25 and up in 1980

Age ranges of $\alpha$ and $\alpha^{\prime}$ identified by treatment group: age 18-34

All other states (affected by federal legislation in 1980):

Treatment: age 18-24 in 1980

Control: all ages prior to 1980, age 25 and up in 1980

Age ranges of $\alpha$ and $\alpha^{\prime}$ identified by treatment group: none 
the period 1950-59, this includes observations on 18-24-year-olds in 1960, 18-34-year-olds in 1970, and 18-44-year-olds in 1980. Note, however, that because no workers in other states who were past the 18-34 age range when these laws were passed are included in the control group, the inclusion of age profile-year interactions implies that the 35-44-year-olds in these latter six states provide no identifÿing information. ${ }^{12}$

Consequently, states that passed age discrimination laws prior to 1950 are necessary to identify effects on age-earnings profiles over a wider age range. In particular, states with laws as of 1940 (Louisiana and Massachusetts) provide the identifying information for workers aged 35 and over. ${ }^{13}$ For example, the Massachusetts law passed in 1937. Thus the treatment group for this state includes those aged $18-24$ in $1940,18-34$ in $1950,18-44$ in $1960,18-54$ in 1970 , and 18-64 in 1980; although, for the reasons explained above, workers aged 25 and over in 1980 provide no identifying information, these states still identify effects on the age-earnings profile through age 54. Given that these two states had age discrimination laws during the entire sample period, the necessary assumption for these states to provide identifying information is that we rule out persistent differences in age-earnings profiles between these states and other states; we explored a similar assumption with respect to employment effects (see col. 6 of table 3), in which case this assumption appeared not to be important.

An alternative strategy providing more identifying information is to define the control group more broadly to include those workers who were already beyond the youngest age group when the age discrimination law passed. In this case, for example, workers aged 25 and over in New York (and the other states that passed laws in 1960) are in the control group for 1960, as are those 35 and over in 1970 and 45 and over in $1980 .{ }^{14}$ This yields more identifying information from the six states that passed age discrimination laws by 1960 because workers in these years and age groups in states that never passed their own age discrimination laws remain in the control group in the years after the federal law takes effect. This allows us to infer the effects of age discrimination legislation by comparing, for example, the earnings of workers in New York who are aged 25-

\footnotetext{
${ }^{12}$ Note that, for the same reason, adding data from the 1990 census would not be helpful.

${ }^{13}$ We do not include Colorado in this group since it is classified as having weak enforcement.

${ }^{14}$ With this broader control group, $\gamma$ and $\gamma^{\prime}$ in eq. (8) (and $\delta$ and $\delta^{\prime}$ defined in eq. [9] below) are identified when state-year interactions are included because we have observations on the treatment and control groups in the same state-year cell.
} 


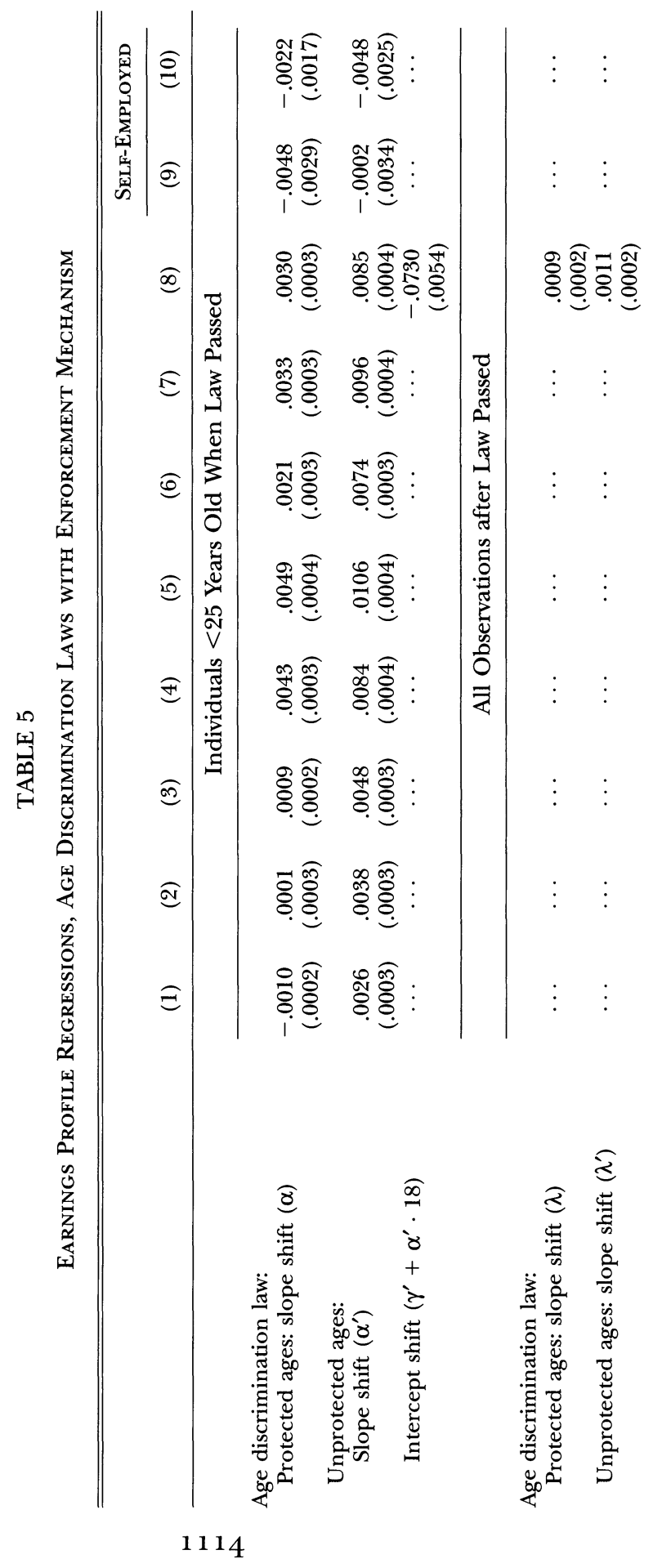




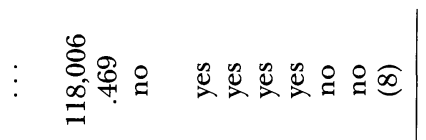

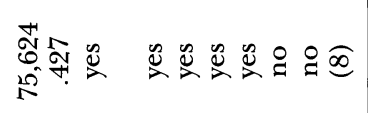

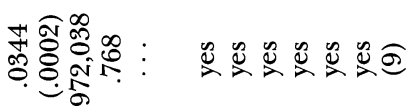

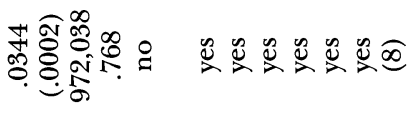

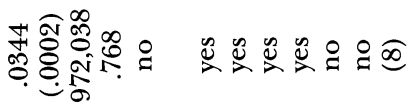

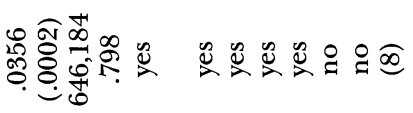

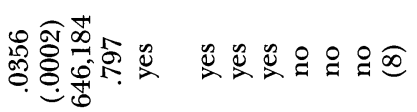

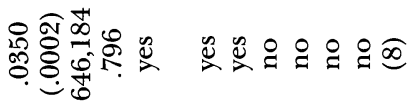

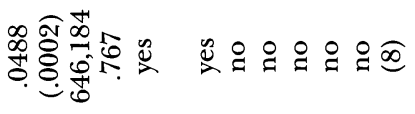

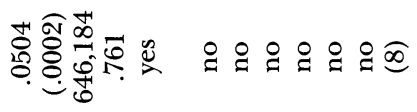

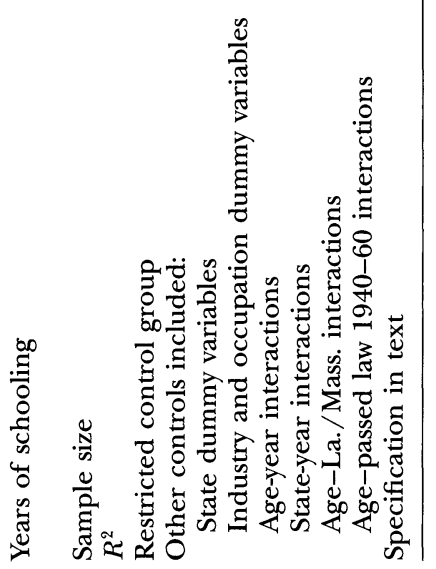

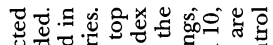

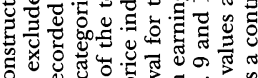

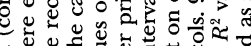

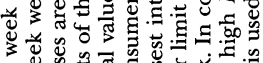

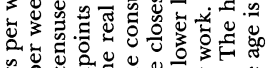

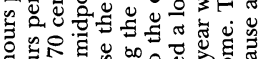
연유 면

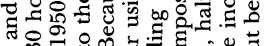
के यें

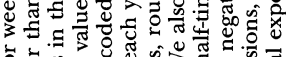
t。 凹

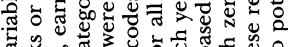

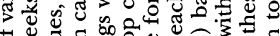

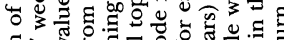

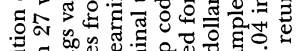

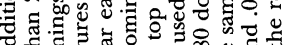
క

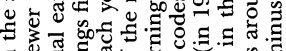

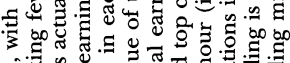
का

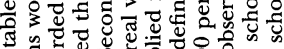

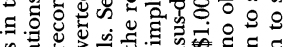
\%

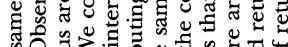

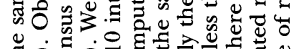

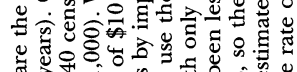
तै के

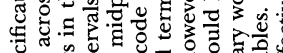
की क.

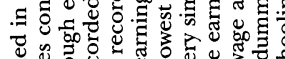

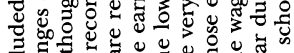

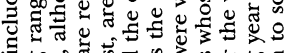

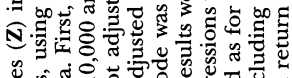

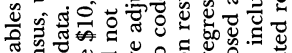

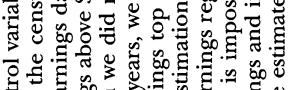

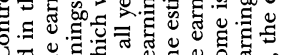

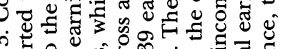
๑ 。

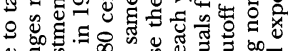

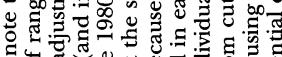

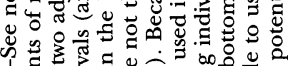
१.气

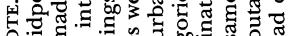

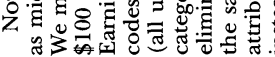


34 in 1980 with the earnings of workers in the same age group in the same year in states that never passed laws and were first affected by the federal law. With this strategy, it is also feasible to check whether the identifying information using the more restrictive control group comes from policy effects or from state-specific differences in age-earnings profiles for the states that had age discrimination laws as of 1940 . We do this by introducing interactions between the age dummy variables and a dummy variable for the two states that-in the specification with the more restrictive control groupprovide much of the identifying information (Louisiana and Massachusetts) and comparing the estimated effects of the age discrimination laws that are now identified only from age discrimination laws passed during the sample period. When we include these interactions (and use the less restrictive control group), we can identify the effects through age 44 because these are the oldest workers who were in the 18-24 age group as of $1960 .{ }^{15}$ In addition, we can add the interactions between age and a dummy variable for the states that passed age discrimination laws in the 1940-60 period, as we did in the employment regressions, to allow these states to have ageearnings profiles different from those of the other states and therefore to identify the effects of age discrimination laws more directly from changes in age-earnings profiles stemming from the enactment of these laws.

Estimates of equation (8) are reported in columns 1-7 of table 5. Columns 1-5 use the restricted control group, and columns 6 and 7 use the broader control group. For reasons discussed above, we focus on estimates of the effect of age discrimination laws on the steepness of earnings profiles for workers in the younger unprotected age group $\left(\alpha^{\prime}\right)$. In column 1 , the estimate of $\alpha^{\prime}$ is positive and significant. The estimate of .0026 indicates that earnings rise by an additional 0.26 percentage point per year as a result of age discrimination laws. Given typical slopes of age-earnings profiles on the order of .03 or so, this represents a substantial effect. We next report results for specifications adding state dummy variables in column 2 , industry and occupation dummy variables in column 3 , and interactions between the age dummy variables and year dummy variables in column 4 . The first two specification changes raise the estimate of $\alpha^{\prime}$, with the estimates in columns 2 and 3 indicating that age discrimination laws boost earnings growth of unprotected workers by $0.38-0.48$ percentage point per year. The estimate in col-

\footnotetext{
${ }^{15}$ Given the much later dates of explicit mandatory retirement prohibitions and the absence of evidence that such prohibitions increase employment, we do not attempt to estimate the effects of such prohibitions on age-earnings profiles.
} 
umn 4 indicates a stronger effect, rising to 0.84 percentage point per year.

Column 5 adds the state-year interactions to the specification to allow for unobserved effects common to individuals in the same state and year. The effect of age discrimination laws in steepening ageearnings profiles is even sharper in this specification, rising to 1.06 percentage points per year for unprotected workers. Column 6 reports results using the specification in column 5, augmented to include in the control group observations on workers who were already in the labor market when age discrimination laws were passed (i.e., who were 25 or older in the census years in which the laws were first in effect). The estimated effect of age discrimination laws on the steepness of age-earnings profiles for the younger, unprotected workers falls to 0.74 percentage point per year but remains strongly statistically significant and still indicates a large effect. Column 7 adds interactions between the age dummy variables and a dummy variable for Louisiana or Massachusetts, and additional interactions of age dummies with a dummy variable for states that passed laws in the 1940-60 period. As with the employment results, these enrichments of the specification have relatively little effect on the results.

Finally, the discussion above of the restricted and broad control groups points to an alternative approach to distinguishing between the effects of age discrimination laws on age-earnings profiles that arise via changes in long-term contracting and those that arise from relative demand shifts. This approach does not require the identifying assumption that relative demand shifts affect equally the wages of all workers within either the protected or unprotected group and thus permits us to estimate the effects of age discrimination laws on the intercepts of age-earnings profiles. In particular, the group of workers who are excluded from the restricted control group but included in the broad control group are those who were already in the market (i.e., aged 25 or older) when the age discrimination laws passed. An alternative way to think about this group is that they are unaffected by changes in long-term incentive contracting-because to a large extent they have already entered into long-term employment relationships-but that they are affected by relative demand shifts as, for example, spot market firms with poor records of hiring older workers begin to do so. Thus we estimate the effects of age discrimination laws on long-term incentive contracts by augmenting equation (8) to allow age discrimination laws to affect those workers in the market but already "older" when the law passed, differentiating between the effects on these workers and workers who enter the labor market after the laws passed. Specifically, we estimate 


$$
\begin{aligned}
Y_{i j t}= & \mathbf{Z}_{i j t} \beta+\mathbf{T}_{t} \beta^{\prime}+\mathbf{S}_{j} \beta^{\prime \prime}+\mathrm{PAD}_{i j t} \cdot \mathrm{AD}_{j t} \cdot \mathrm{YNG}_{i j t} \gamma \\
& +\left(1-\mathrm{PAD}_{i j t}\right) \cdot \mathrm{AD}_{j t} \cdot \mathrm{YNG}_{i j t} \gamma^{\prime} \\
& +\mathrm{AGE}_{i j t} \cdot \mathrm{PAD}_{i j t} \cdot \mathrm{AD}_{j t} \cdot \mathrm{YNG}_{i j t} \alpha \\
& +\mathrm{AGE}_{i j t} \cdot\left(1-\mathrm{PAD}_{i j t}\right) \cdot \mathrm{AD}_{j t} \cdot \mathrm{YNG}_{i j t} \alpha^{\prime} \\
& +\mathrm{PAD}_{i j t} \cdot \mathrm{AD}_{j t} \delta+\left(1-\mathrm{PAD}_{i j t}\right) \cdot \mathrm{AD}_{j t} \delta^{\prime} \\
& +\mathrm{AGE}_{i j t} \cdot \mathrm{PAD}_{i j t} \cdot \mathrm{AD}_{j t} \lambda+\mathrm{AGE}_{i j t} \cdot\left(1-\mathrm{PAD}_{i j t}\right) \cdot \mathrm{AD}_{j t} \lambda^{\prime}+\epsilon_{i j t},
\end{aligned}
$$

where YNG is a dummy variable equal to one for workers who were less than 25 years old when an age discrimination law passed. In this specification, $\lambda$ and $\lambda^{\prime}$ capture the effects of age discrimination laws on the steepness of age-earnings profiles of all workers in states in which such laws pass, and $\delta$ and $\delta^{\prime}$ capture the effects of such laws on the intercepts of their earnings profiles; we assume that the effects captured in the $\lambda$ 's and $\delta$ 's reflect relative demand shifts. In contrast, $\alpha$ and $\alpha^{\prime}$ capture the difference in the effects of such laws for workers who entered the labor market after such laws passed, thus serving as difference-in-difference estimators of the effects of age discrimination laws, netting out the effects of relative demand shifts. In addition, because the intercept shifts $\left(\gamma\right.$ and $\left.\gamma^{\prime}\right)$ no longer serve to capture the relative demand shifts, in equation (9) these parameters can be interpreted as capturing the effects of age discrimination laws via long-term contracting. Thus, with this specification and identifying assumption, we can more readily interpret the estimated effects of age discrimination laws on the slopes and the intercepts of earnings profiles as arising from changes in Lazear contracting.

Estimates of equation (9) are reported in column 8 of table 5. First, the results for all observations after a law passed (which include those workers who were older when the law passed) indicate that relative demand may have shifted toward older workers within the group of unprotected workers; the estimate of $\lambda^{\prime}$ is positive (.0011, indicating that earnings are increased by 0.11 percentage point more for each year of age). More important, the estimates of $\alpha^{\prime}$ remain positive and significant, and only a bit smaller than before; the estimates indicate that age discrimination laws increase the slopes of age-earnings profiles for younger, unprotected workers by 0.85 percentage point per year, now measured relative to other workers in the labor market but not workers who were older when these laws passed. ${ }^{16}$ We also report the shift in earnings implied by the estimates

${ }^{16}$ The estimates were nearly identical when we omitted the interactions of the age dummies with a dummy variable for Louisiana or Massachusetts and with a dummy variable for states that passed age discrimination laws between 1940 and 1960 . 
for an 18-year-old in the unprotected group (the "intercept" of the earnings profile). This estimate (of $\left.\gamma^{\prime}+\alpha^{\prime} \cdot 18\right)$ indicates that initial earnings are lowered by 7.3 percent by age discrimination laws, also consistent with increased use of Lazear contracts.

Increased use of long-term incentive contracts also implies greater present discounted values of earnings profiles. As noted earlier, we do not think that our data are sufficiently rich to obtain convincing evidence on this question, in part because we do not have data on actual tenure spells. Nonetheless, we did some illustrative calculations. For example, when 3 percent annual growth of earnings is assumed and a 30-year period is used, the intercept reduction of 7.30 percent and slope increase of 0.85 percentage point (as in col. 8 of table 5) result in a higher present discounted value of the earnings stream for discount rates of 11 percent and below. With higher annual growth rates of earnings, or longer horizons, the steeper profiles have higher present values for even higher discount rates. Thus, for discount rates that are not too (perhaps unreasonably) high, these calculations based on our estimates suggest that age discrimination laws increase lifetime earnings, as would be expected if such laws strengthen long-term commitments.

We close by considering some other possible explanations for our findings. First, age discrimination laws at the state level could induce migration. Economic theory would predict that this migration would, in general, arbitrage away any advantages posed by age discrimination laws. In terms of employment, if age discrimination laws enhance opportunities for older workers, we might expect general in-migration of older individuals and perhaps selection of those most likely to take advantage of these opportunities (i.e., the most employable). This suggests that our estimated employment effects for older workers, reported in table 3, may be upward biased. In terms of the more important effects of such laws on age-earnings profiles, things are a bit more complicated. If we take seriously the calculations regarding present value of earnings, the bias from this arbitrage works in our favor, in that evidence that age discrimination laws boost lifetime earnings would be stronger in the absence of migration. However, if we focus solely on the steepening of age-earnings profiles, migration could cut either way. If age discrimination laws generate in-migration of relatively younger workers to take advantage of stronger long-term contracts, then-especially because some of these workers probably remain in the spot market-the price of young labor would fall and we might find spurious evidence that age discrimination laws tend to steepen age-earnings profiles. On the other hand, a tendency of such laws to generate in-migration of older workers would obscure evidence of steepening, in which case 
our evidence of steepening earnings profiles should be regarded as even stronger.

To explore this issue, we used information available in the 1940 , 1960,1970 , and 1980 censuses on whether the individual had lived in another state five years earlier. (In 1950 the question refers to one year earlier and hence is not fully comparable.) After verifying that the results reported in the earlier tables were unchanged by dropping data from the 1950 census, we estimated linear probability models for whether the individual was an in-migrant from another state. ${ }^{17}$ We estimated three different models corresponding closely to the specifications in columns 5,6 , and 7 of table 3 , although instead of the age discrimination law variables used in that table, we simply added interactions between the categorical age variables and whether there was an age discrimination law. ${ }^{18}$ As reported in table 6 , there are strong age patterns of mobility indicating, not surprisingly, that older individuals are less likely to be recent in-migrants. However, the age-law interactions go the other way, with the estimates indicating that age discrimination laws induce in-migration of older individuals; the relationship is nearly monotonically increasing with age. As a general matter, this apparent responsiveness to age discrimination laws is quite striking, indicating that caution is necessary in inferring causal effects from cross-state variation in legislation. As noted above, this migration response implies that our estimates of the increases in employment among older workers resulting from age discrimination laws are overstated. With respect to our key evidence regarding the effects of age discrimination laws on age-earnings profiles, however, the evidence on migration implies that our finding that age discrimination laws lead to steeper age-earnings profiles is not spurious and would be even stronger in the absence of migration responses to such laws.

Finally, it is conceivable that the evidence that age discrimination laws steepen age-earnings profiles stems from other sources of changes in relative earnings at different ages that happen to coincide with the advent of age discrimination laws, rather than from effects of these laws. We have controlled for fixed state effects, year effects, and state-year effects, as well as changes in the demographic composition and education levels of the workforce in each state via the individual-level controls. But we cannot rule out on a priori grounds the influence of other factors that vary with state and year,

\footnotetext{
${ }^{17}$ We know the state from which the person came only in some census years, so we do not use this information.

${ }^{18}$ We do not use interactions with whether or not the worker was currently protected by the law since currently unprotected workers may have incentives to move in to take advantage of such laws.
} 


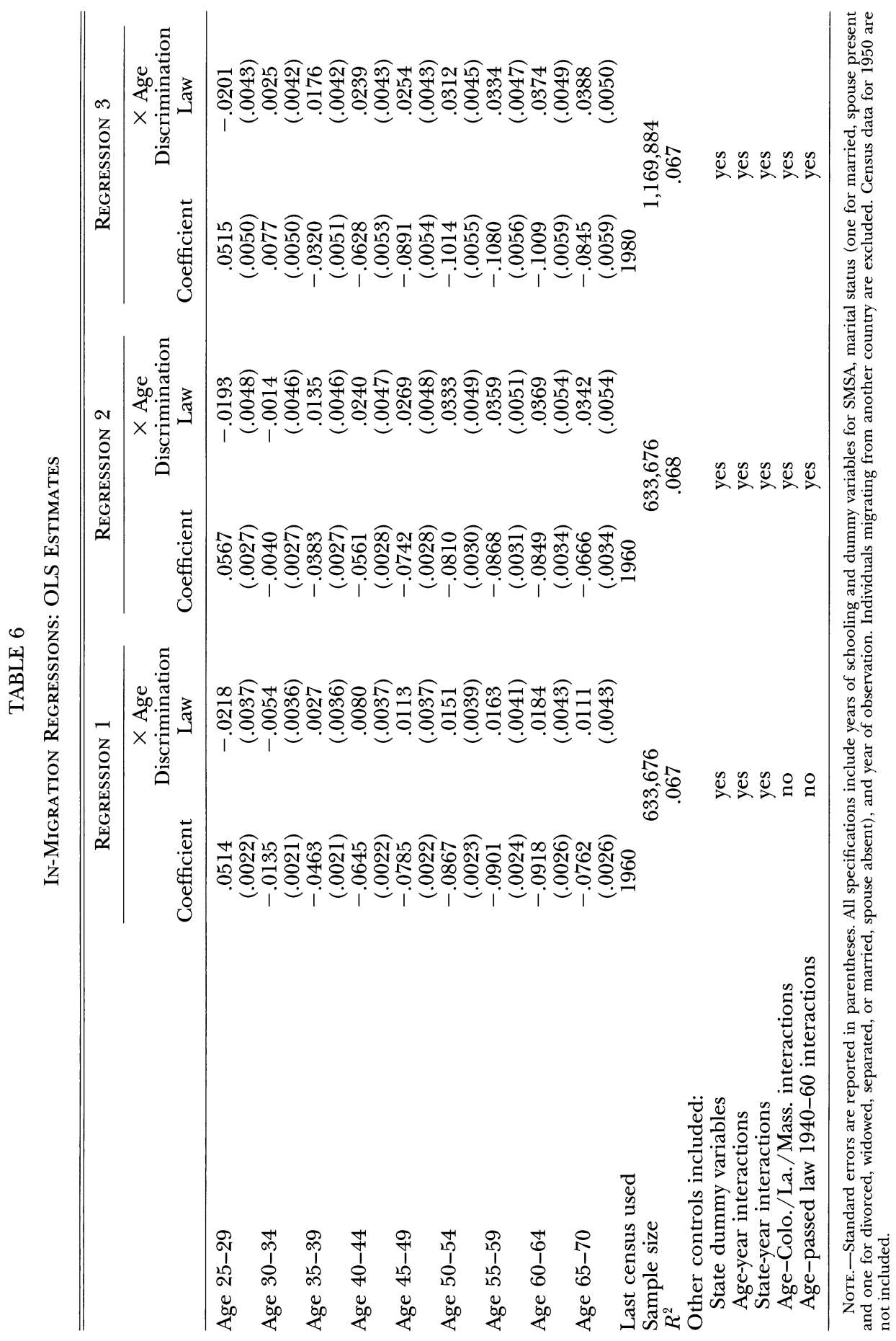


although we regard it as unlikely that they would have generated the results reported in earlier tables.

Nonetheless, to test for this possibility, we consider evidence for self-employed workers, for whom Lazear contracts should be irrelevant (Lazear and Moore 1984). If we observe the same relationship between age discrimination laws and steepening of age-earnings profiles for self-employed workers as for wage and salary workers, we would be suspicious that we are detecting changes induced by these laws via strengthened Lazear contracts. On the other hand, if we fail to find any corresponding evidence among the selfemployed, then we would be more inclined to believe that our results for wage and salary workers reflect changes in Lazear contracting stemming from age discrimination laws.

The estimates are presented in columns 9 and 10 of table 5. Because self-employment income is not available in 1940, we can carry out this estimation beginning only in 1950. We first replicated all the preceding estimations using only the 1950-80 data and the results were unchanged, so any differences are attributable solely to using the self-employed. In addition, in some years, only combined business and farm income is reported in the census data, so we use their sum for each year. Finally, because the issue of changes in relative demand for self-employed workers induced by age discrimination laws is less pertinent, we report only estimates of specification (8). We further limit attention to a subset of specifications from the earlier tables, although the results were similar across the full set of specifications, and the standard errors were only slightly lower if the state-year interactions were excluded.

In brief, in contrast to the results for wage and salary workers, the results provide no evidence that age discrimination laws are associated with steeper age-earnings profiles (or lower intercepts) for the self-employed. In fact, for the unprotected workers on whom we focus with respect to this question (i.e., the estimates of $\alpha^{\prime}$ ), the estimates are in the opposite direction. ${ }^{19}$ These results lead us to conclude with more confidence that our evidence for wage and salary workers represents causal effects of age discrimination laws that operate only on wage and salary workers - the types of effects that we would expect if such laws strengthen Lazear contracts.

\footnotetext{
${ }^{19}$ An alternative possibility is that self-employment income is measured too imprecisely to observe the relationships we observe for wage and salary workers, even if they exist for the self-employed. However, given the standard errors of the estimates of $\alpha^{\prime}$ that we obtain for the self-employed, estimates of $\alpha^{\prime}$ of the magnitudes we obtain for the non-self-employed would still be significant. In addition, many of the estimates of $\alpha^{\prime}$ are negative rather than positive, which cannot be attributed to random measurement error in self-employment income.
} 


\section{Conclusions}

Lazear's critique of the Age Discrimination in Employment Act was based on the view that employers needed to be able to discriminate on the basis of age in order to implement long-term incentive contracts, because such contracts, while acceptable ex ante to both workers and firms, are unacceptable to workers ex post. In this view, laws prohibiting age discrimination would reduce the use of long-term incentive contracts. An alternative perspective on such laws is that they serve as a precommitment device that makes credible the longterm commitment to workers that firms must make under long-term incentive contracts, by making it costly for firms to dismiss older workers to whom payments in excess of current marginal product are owed. Forcing workers to retire at some point (in Lazear's model, when the present values of the streams of wages and marginal products are equal) may appear to be made more difficult if mandatory retirement is prohibited, but under the ADEA, firms retain the ability to offer strong financial incentives to encourage retirement at any age they choose. Thus this alternative perspective suggests that the predominant effect of the ADEA and other age discrimination laws may have been to strengthen the bonds between workers and firms, thus enabling greater use of Lazear contracts.

We assess evidence on these alternative perspectives on the ADEA by estimating the effects of age discrimination laws on the steepness of age-earnings profiles. If long-term incentive contracts are strengthened and become more prevalent, average age-earnings profiles should steepen for workers who enter the labor market after age discrimination laws are passed; if they are weakened, these profiles should flatten. We also estimate the effects of such laws on employment of protected and unprotected workers. We find that age discrimination laws boost the relative employment of older workers. More important, the results indicate that age discrimination laws lead to steeper age-earnings profiles in the labor market. While possibly consistent with other interpretations, one interpretation of this evidence consistent with the model we lay out is that age discrimination laws strengthen bonds between workers and firms, leading to greater use of Lazear contracts in labor markets and hence more likely increasing than decreasing labor market efficiency.

\section{References}

Albert, Rory J., and Schelberg, Neal S. "Benefit Plans Redefined under ADEA." Pension World (October 1989), pp. 45-48.

Bureau of National Affairs. Fair Employment Practices. Washington: Bur. Nat. Affairs, 1994. 
$\rightarrow$ Burkhauser, Richard V., and Quinn, Joseph F. "Is Mandatory Retirement Overrated? Evidence from the 1970s." J. Human Resources 18 (Summer 1983): 337-58.

$\rightarrow$ Carmichael, H. Lorne. "Firm-Specific Human Capital and Promotion Ladders." Bell J. Econ. 14 (Spring 1983): 251-58.

Epstein, Richard A. Forbidden Grounds: The Case against Employment Discrimination Laws. Cambridge, Mass.: Harvard Univ. Press, 1992.

$\rightarrow$ Fields, Gary S., and Mitchell, Olivia S. "Economic Determinants of the Optimal Retirement Age: An Empirical Investigation.” J. Human Resources 19 (Spring 1984): 245-62.

- "Early Retirement in the United States." Manuscript. Ithaca, N.Y.: Cornell Univ., 1986.

Ford, Gary M., and Horn, Paul S. "Assessing the Impact of the Older Workers Act and the ADA." J. Pension Planning and Compliance 18 (Spring 1992): 1-30.

Friedman, Lawrence M. Your Time Will Come: The Law of Age Discrimination and Mandatory Retirement. New York: Sage Found., 1984.

Gold, Michael Evan. An Introduction to the Law of Employment Discrimination. Ithaca, N.Y.: ILR Press, 1993.

$\rightarrow$ Gustman, Alan L., and Steinmeier, Thomas L. "A Structural Retirement Model." Econometrica 54 (May 1986): 555-84.

$\rightarrow$ Hellerstein, Judith K; Neumark, David; and Troske, Kenneth R. "Wages, Productivity, and Worker Characteristics: Evidence from Plant-Level Production Functions and Wage Equations." J. Labor Econ. 17 (July 1999): 409-46.

$\rightarrow$ Holmstrom, Bengt. "Contractual Models of the Labor Market." A.E.R. Papers and Proc. 71 (May 1981): 308-13.

$\rightarrow$ Hurd, Michael D. "Research on the Elderly: Economic Status, Retirement, and Consumption and Saving." J. Econ. Literature 28 (June 1990): 565637.

Kertzer, Susan Dana. “Perspectives on Older Workers: Maine’s Prohibition of Mandatory Retirement.” Maine Law Rev. 33 (April 1981): 156-94.

$\rightarrow$ Kotlikoff, Laurence J., and Gokhale, Jagadeesh. 'Estimating a Firm's AgeProductivity Profile Using the Present Value of Workers' Earnings." Q.J.E. 107 (November 1992): 1215-42.

Kotlikoff, Laurence J., and Wise, David A. "Labor Compensation and the Structure of Private Pension Plans: Evidence for Contractual versus Spot Labor Markets.' In Pensions, Labor, and Individual Choice, edited by David A. Wise. Chicago: Univ. Chicago Press (for NBER), 1985.

- "Employee Retirement and a Firm's Pension Plan." In The Economics of Aging, edited by David A. Wise. Chicago: Univ. Chicago Press (for NBER), 1989.

Lang, Kevin. "Why Was There Mandatory Retirement?" J. Public Econ. 39 (June 1989): 127-36.

$\rightarrow$ Lazear, Edward P. "Why Is There Mandatory Retirement?" J.P.E. 87 (December 1979): 1261-84.

- "Incentive Effects of Pensions." In Pensions, Labor, and Individual Choice, edited by David A. Wise. Chicago: Univ. Chicago Press (for NBER), 1985.

—. Personnel Economics. Cambridge, Mass.: MIT Press, 1995.

$\rightarrow$ Lazear, Edward P., and Moore, Robert L. "Incentives, Productivity, and Labor Contracts."' Q.J.E. 99 (May 1984): 275-96.

Medoff, James L., and Abraham, Katharine G. "Experience, Performance, and Earnings." Q.J.E. 95 (December 1980): 703-36. 
Miller, David G. "Age Discrimination in Employment: The Problem of the Older Worker." New York Univ. Law Rev. 41 (April 1966): 383-424.

Mitchell, Olivia S., and Fields, Gary S. "Rewards for Continued Work: The Economic Incentives for Postponing Retirement." In Horizontal Equity, Uncertainty, and Economic Well-Being, edited by Martin David and Timothy Smeeding. Chicago: Univ. Chicago Press (for NBER), 1985.

Moulton, Brent R. "Random Group Effects and the Precision of Regression Estimates." J. Econometrics 32 (August 1986): 385-97.

Nalebuff, Barry, and Zeckhauser, Richard J. "Pensions and the Retirement Decision." In Pensions, Labor, and Individual Choice, edited by David A. Wise. Chicago: Univ. Chicago Press (for NBER), 1985.

Northrup, James P. Old Age, Handicapped, and Vietnam-Era Antidiscrimination Legislation. Philadelphia: Univ. Pennsylvania, Wharton School, Indus. Relations Unit, 1978.

Rees, Albert, and Smith, Sharon P. Faculty Retirement in the Arts and Sciences. Princeton, N.J.: Princeton Univ. Press, 1991.

Ross, Susan C. The Rights of Women: The Basic ACLU Guide to a Woman's Rights. Toronto: American Civil Liberties Union, 1973.

Ruhm, Christopher J. "Determinants of the Timing of Retirement." In Bridges to Retirement: Older Workers in a Changing Labor Market, edited by Peter B. Doeringer. Ithaca, N.Y.: ILR Press, 1990.

Schachter, Kristoff, Ross, Sprague \& Curiale. Employment Practices for the Professional Firm. New York: Executive Enterprises Pubs. Co., 1985.

Schelling, Thomas C. "Strategic Relationships in Dying." In Death and Decision, edited by Ernan McMullin. Boulder, Colo.: Westview (for American Assoc. Advancement Sci.), 1978.

. "Ethics, Law, and the Exercise of Self-Command." In The Tanner Lectures on Human Values, vol. 4, edited by Sterling M. McMurrin. Salt Lake City: Univ. Utah Press, 1983.

$\rightarrow$ Slade, Frederic P. "Retirement Status and State Dependence: A Longitudinạl Study of Older Men." J. Labor Econ. 5 (January 1987): 90-105.

Stacy, Donald R. "Effect of the Age Act on Employee Benefit Plan Design." J. American Soc. CLU and ChFC 44 (May 1990): 62-64.

U.S. Department of Labor. The Older American Worker. Washington: Government Printing Office, 1965. (a)

- The Older American Worker: Age Discrimination in Employment. Report of the Secretary of Labor to Congress, sec. 715 of the Civil Rights Act of 1964 Research Material. Washington: Government Printing Office, 1965. (b)

- Women's Bureau. Time of Change: 1983 Handbook on Women Workers. Washington: Government Printing Office, 1983.

Wendt, Ann C.; Slonaker, William M.; and Coleman, Joseph W. "Employment Discrimination Is Sex-Blind." SAM Advanced Management J. 58 (Spring 1993): 28-33. 